\title{
The Open Access Advantage for American Law Reviews
}

James M. Donovan, Caroline Osborne and Carol A. Watson 


\section{Carol A. Watson}

University of Georgia School of Law 


\section{Law Review Publication}

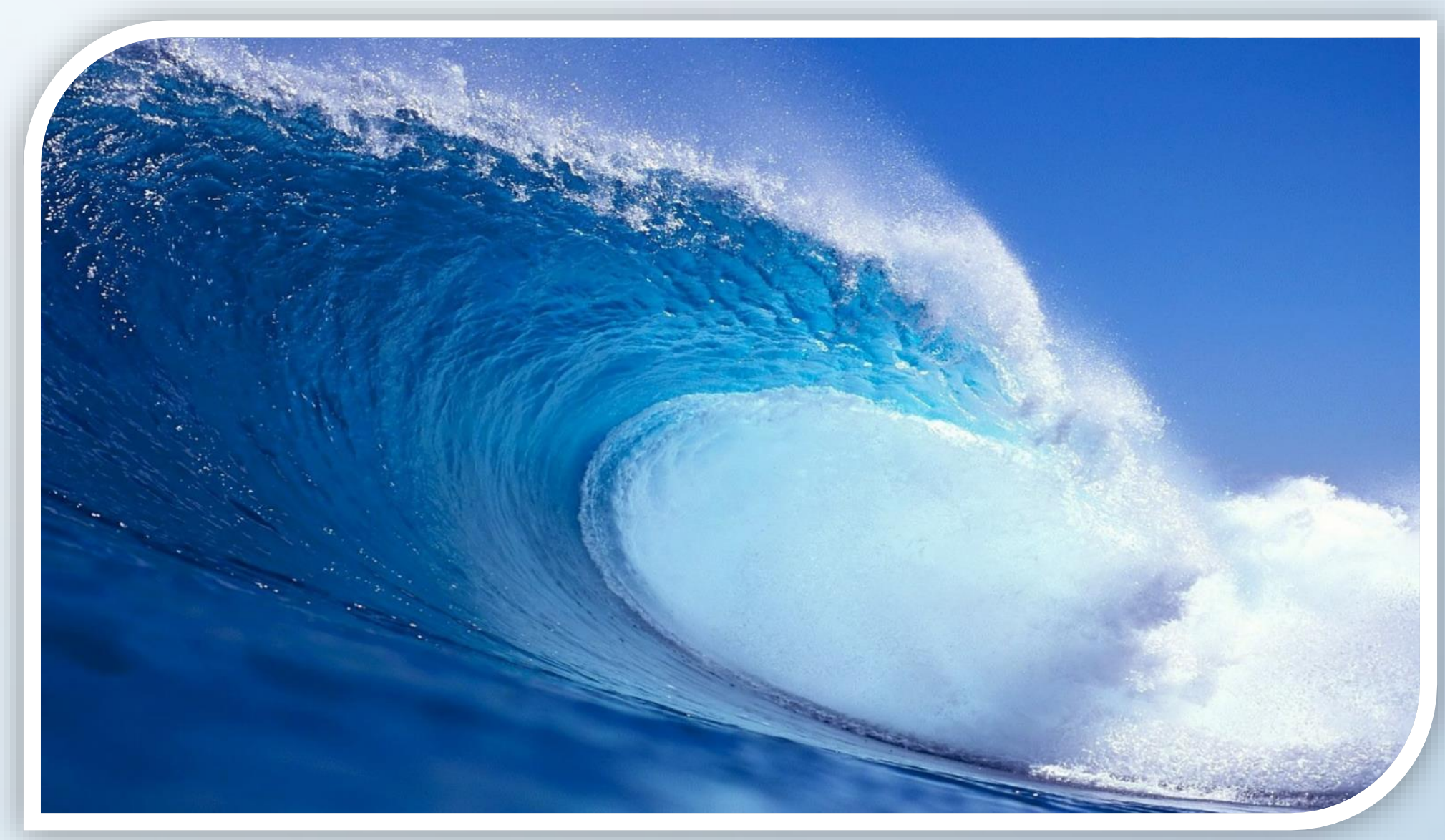


Why Advocate for Open Access to Legal Scholarship?

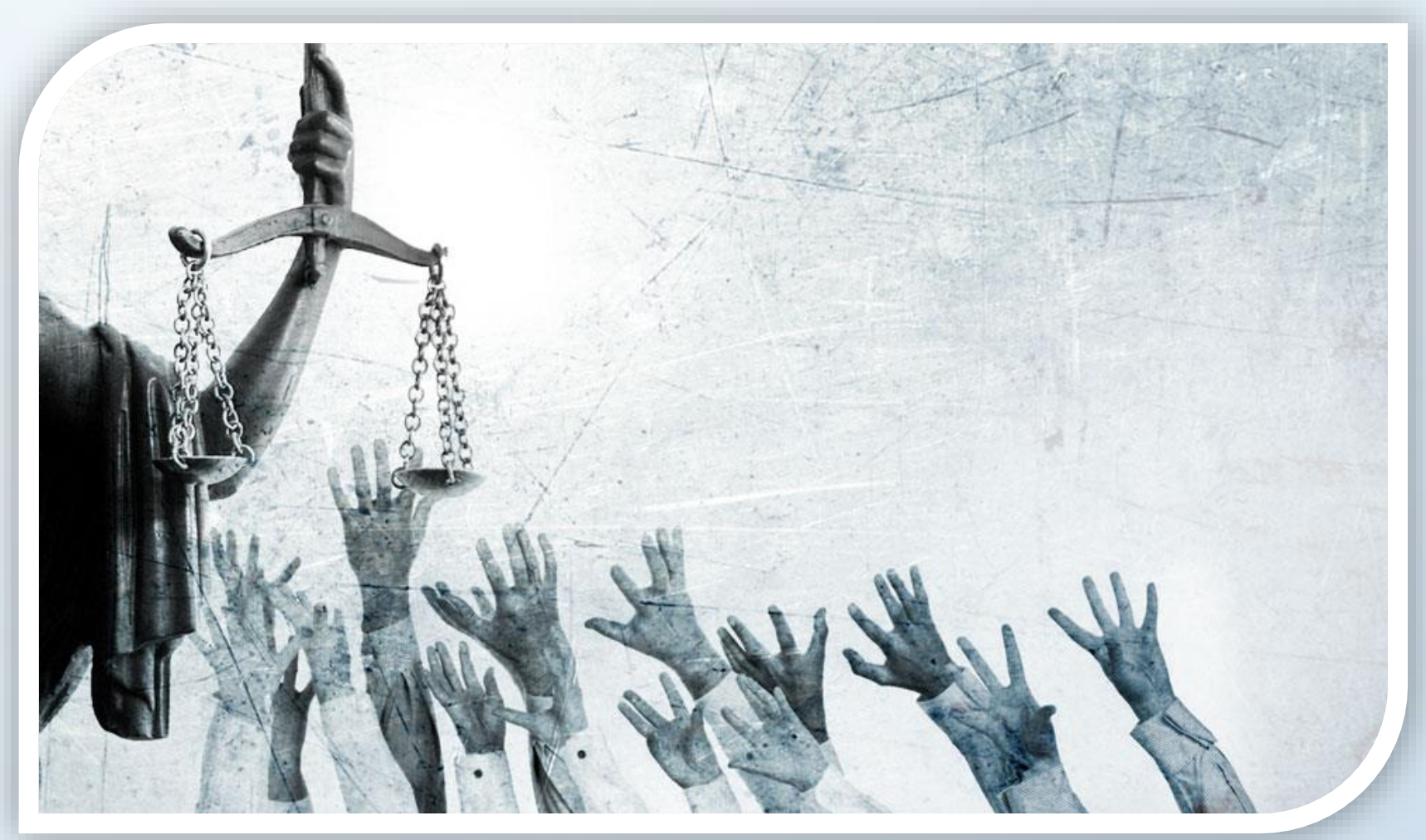

Access to Justice 
Why Advocate for Open Access to Legal Scholarship?

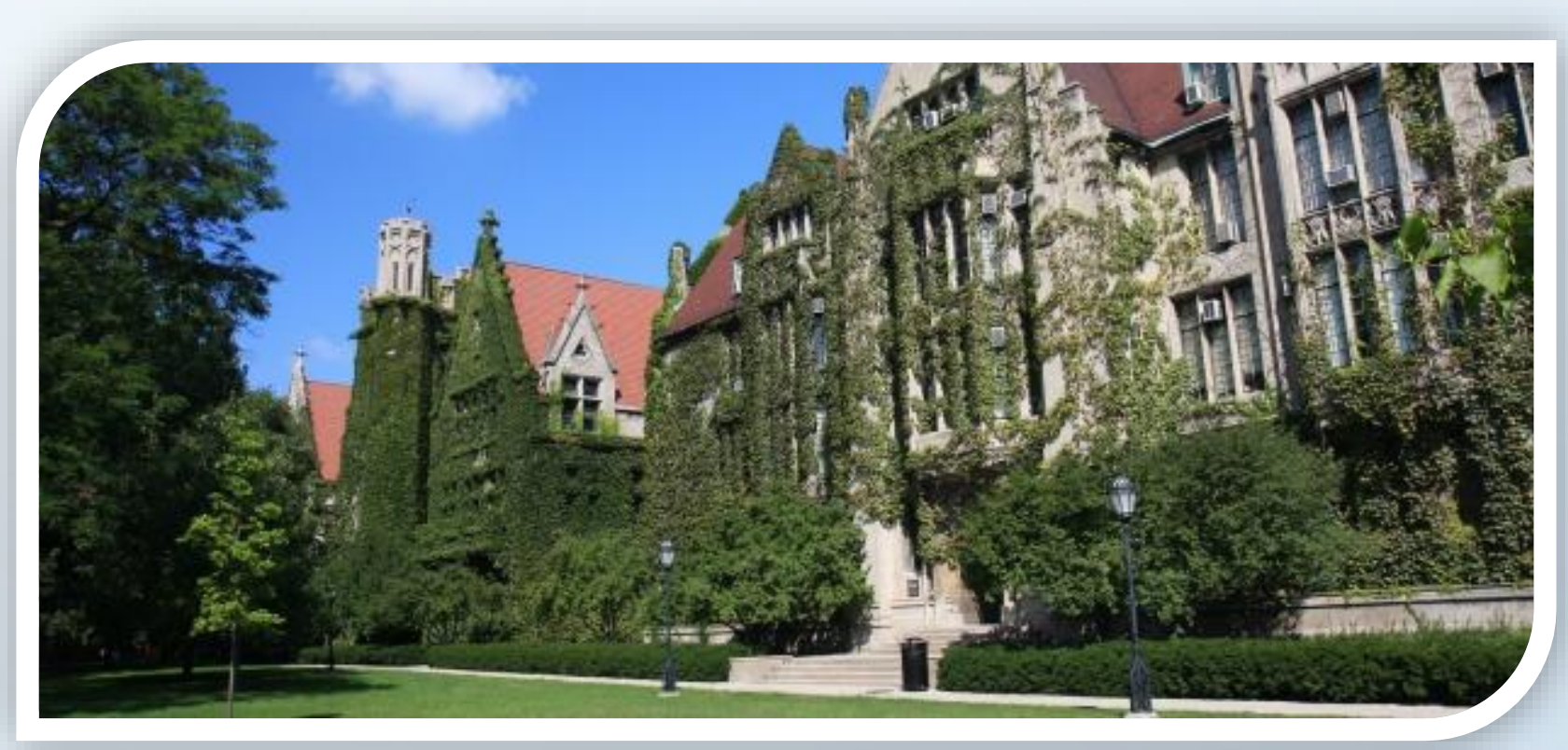

Advancement of Knowledge 
Why Advocate for Open Access to Legal Scholarship?

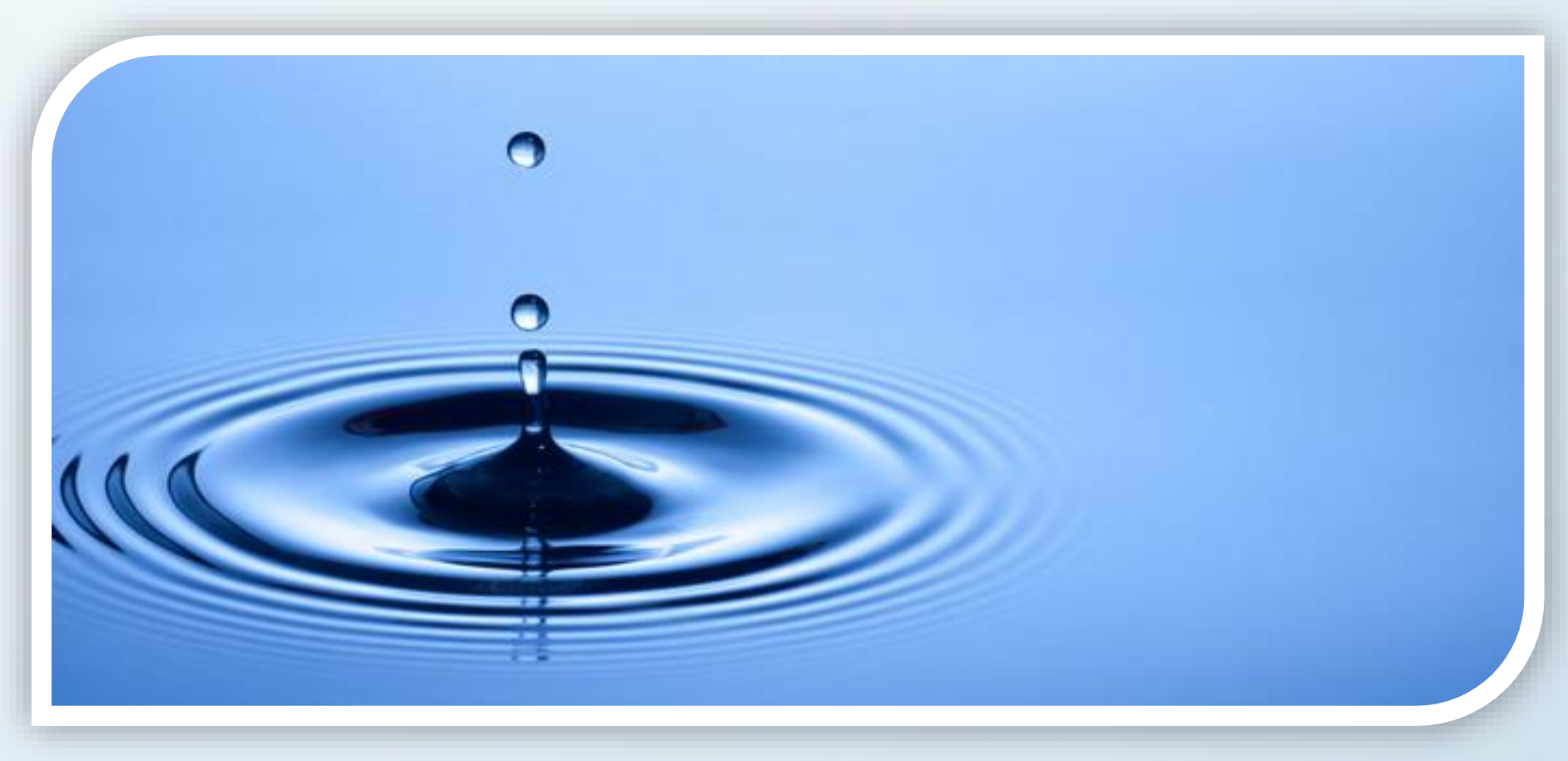

Scholarly Impact 


\section{Open Access Impact Studies $336 \%$ nature}

Free online availability substantially increases a paper's impact

Steve Lawrence

NEC Research Institute

4 Independence Way, Princeton, NJ 08540

lawrence@research.nj.nec.com

The volume of scientific literature far exceeds the ability of scientists to identify and use all relevant information. The ability to locate relevant research quickly will dramatically improve communication and scientific progress. Although availability varies greatly by discipline, more than a million research articles are now freely available on the web.

Here we investigate the impact of free online availability by analysing citation rates. Online availability of an article may not greatly improve access and impact without efficient and comprehensive search services; a substantial percentage of the literature needs to be indexed by these search services before scientists consider them useful. In computer science, a substantial percentage of the literature is online and available through search engines

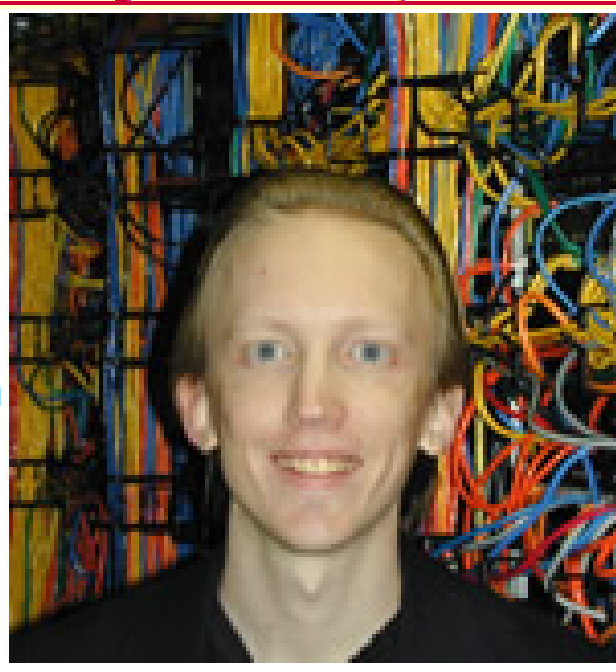

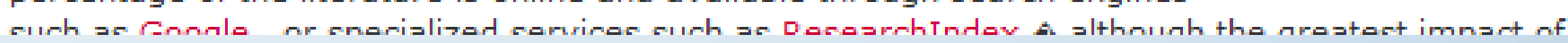




\section{Legal Scholarship OA Impact Studies}

- Chawki Hajjemet al., Ten-Year Cross-Disciplinary Comparison of the Growth of Open Access and How It Increases Research Citation Impact, IEEE data(base), Engineering Bull., Dec. 2005

- James M. Donovan \& Carol A. Watson, Citation Advantage of Open Access Legal Scholarship, 103 L. LIB. J. 553 (2011)

- $58 \%$ citation advantage 


\section{History of Open Access in Legal Academia}

- 1990s - a few legal scholars posted preprints on their personal websites

- 1992 - Cornell's Legal Information Institute (LII)

- 1994 - SSRN Legal Scholarship Network

- 1996 - Jurist

- 1999 - BePress 


\section{History of Open Access in Legal Academia}

- 1998 - Duke legal journals freely accessible online

- 2005 - Duke Law online repository

- 2005 - AALL Open Access Task Force

- 2005 - Open Access Law Program drafted:

- Open Access Law Journal Principles

- Open Access Law Model Publication Agreement

- Open Access Law Author Pledge

- 2006 - Lewis \& Clark Law Review Open Access Symposium Issue 
History of Open Access in Legal Academia

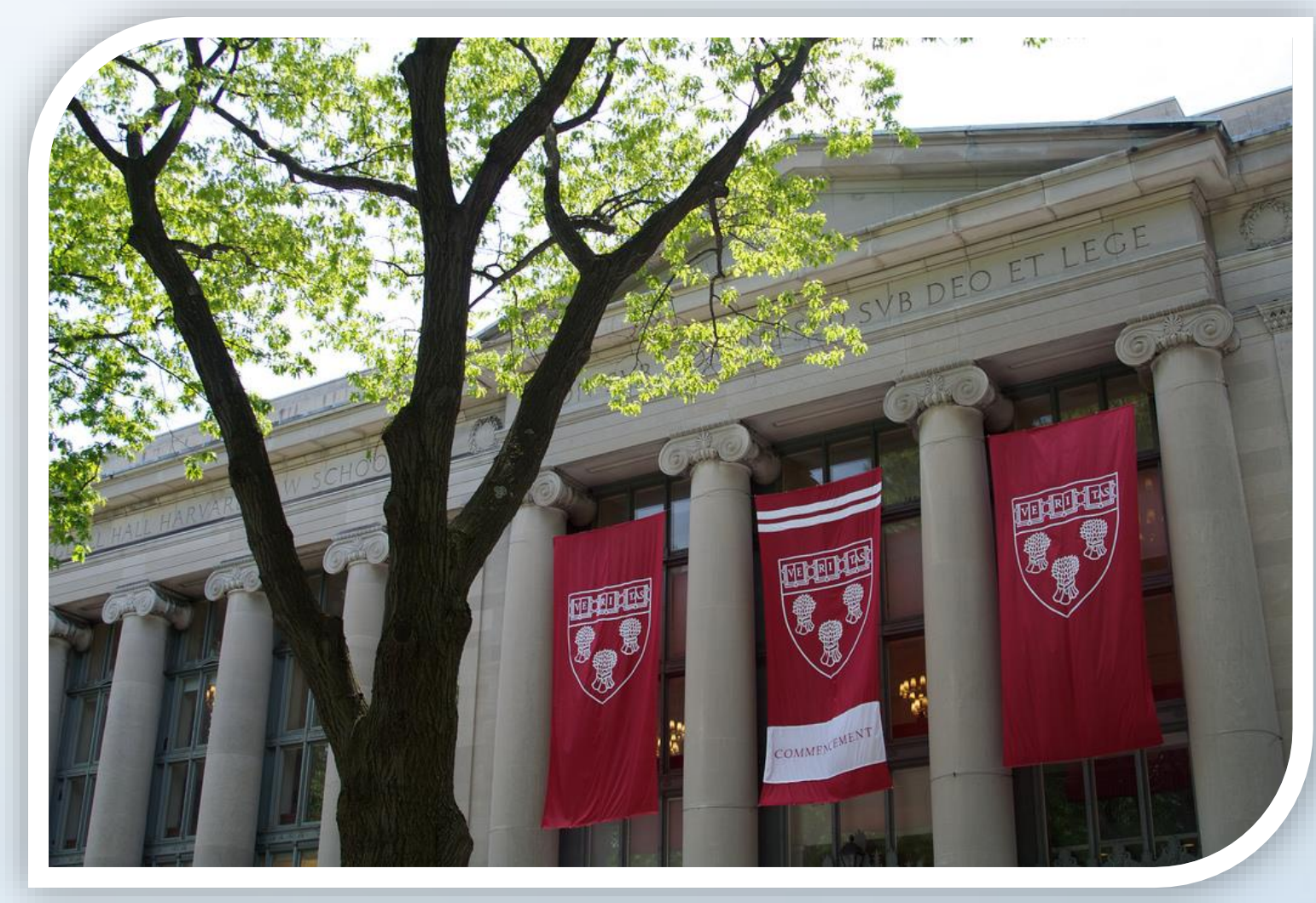

2008 - Harvard Law Faculty Vote Unanimously to Make Scholarship Available Via Free Online Repository 


\section{History of Open Access in Legal Academia}

\section{9 - Durham Statement on Open Access to Legal Scholarship}

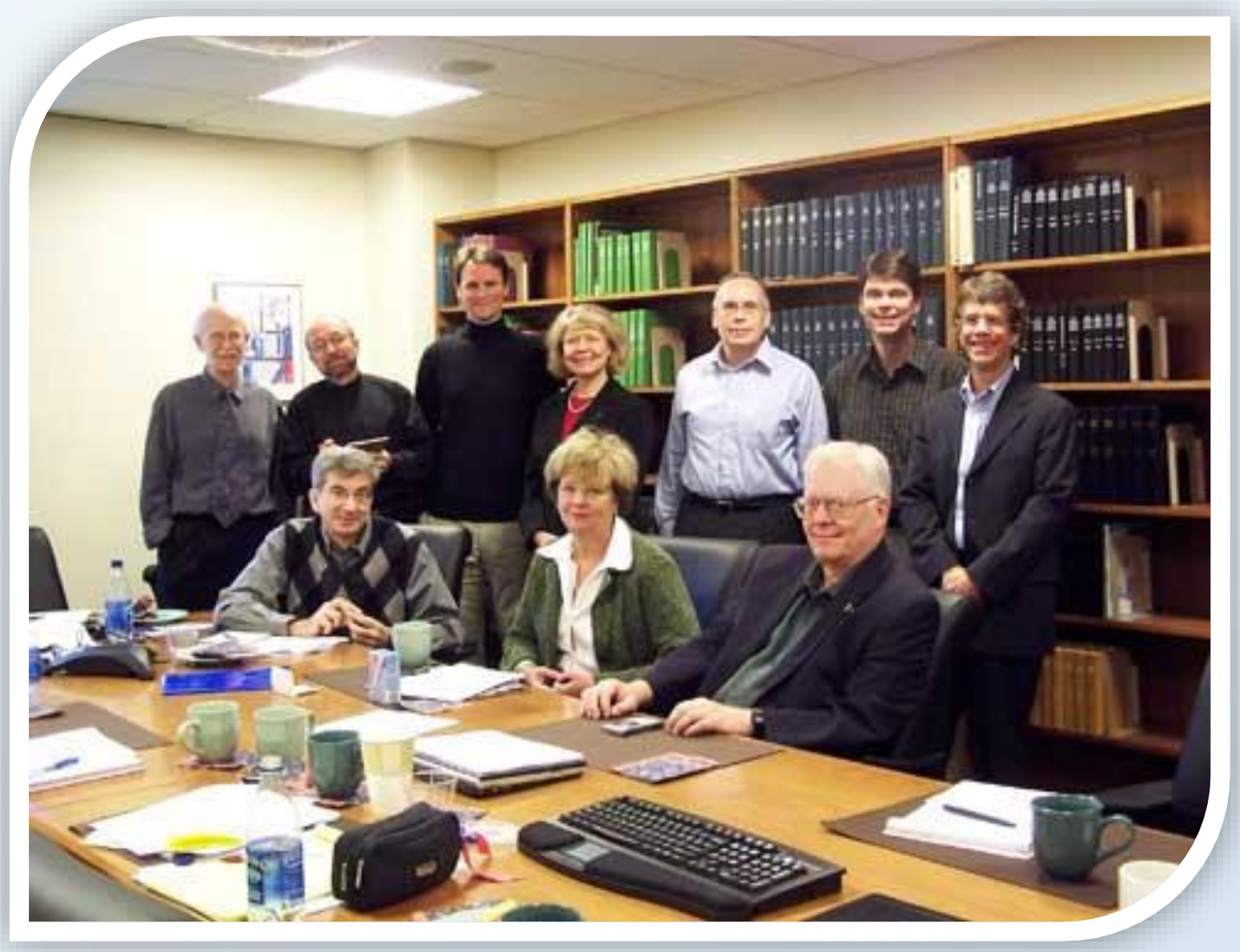

- Dick Danner, Duke

- Radu Popa, NYU

- John Palfrey, Harvard

- Claire Germain, Cornell

- Paul George, University of Pennsylvania

- Jim McMasters, Northwestern

- Blair Kauffman, Yale

- Paul Lomio, Stanford

- Judith Wright, University of Chicago

- Terry Martin, University of Texas 


\section{History of Open Access in Legal Academia}

\section{9- Durham Statement on Open Access to Legal Scholarship}

- Call to Action: We therefore urge every U.S. law school to commit to ending print publication of its journals and to making definitive versions of journals and other scholarship produced at the school immediately available upon publication in stable, open, digital formats, rather than in print.

- We also urge every law school to commit to keeping a repository of the scholarship published at the school in a stable, open, digital format. Some law schools may choose to use a shared regional online repository or to offer their own repositories as places for other law schools to archive the scholarship published at their school.

- Repositories should rely upon open standards for the archiving of works, as well as on redundant formats, such as PDF copies. We also urge law schools and law libraries to agree to and use a standard set of metadata to catalog each article to ensure easy online public indexing of legal scholarship.

- As a measure of redundancy, we also urge faculty members to reserve their copyrights to ensure that they too can make their own scholarship available in stable, open, digital formats. All law journals should rely upon the AALS model publishing agreement as a default and should respect author requests to retain copyrights in their scholarship. 


\section{Caroline Osborne}

Washington \& Lee School of Law 
The SSRN Factor

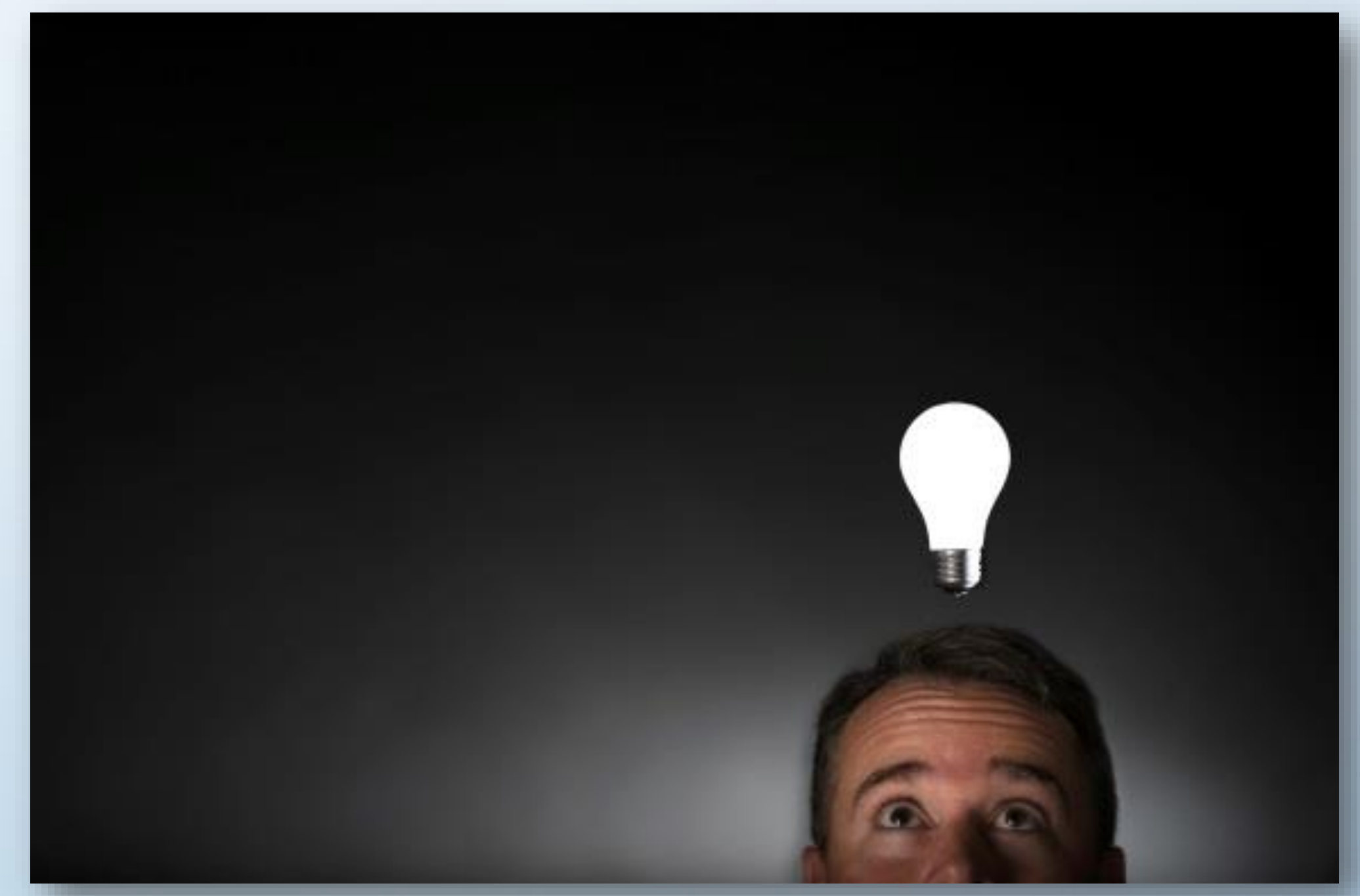




\section{Will posting in multiple places decrease my SSRN download count?}

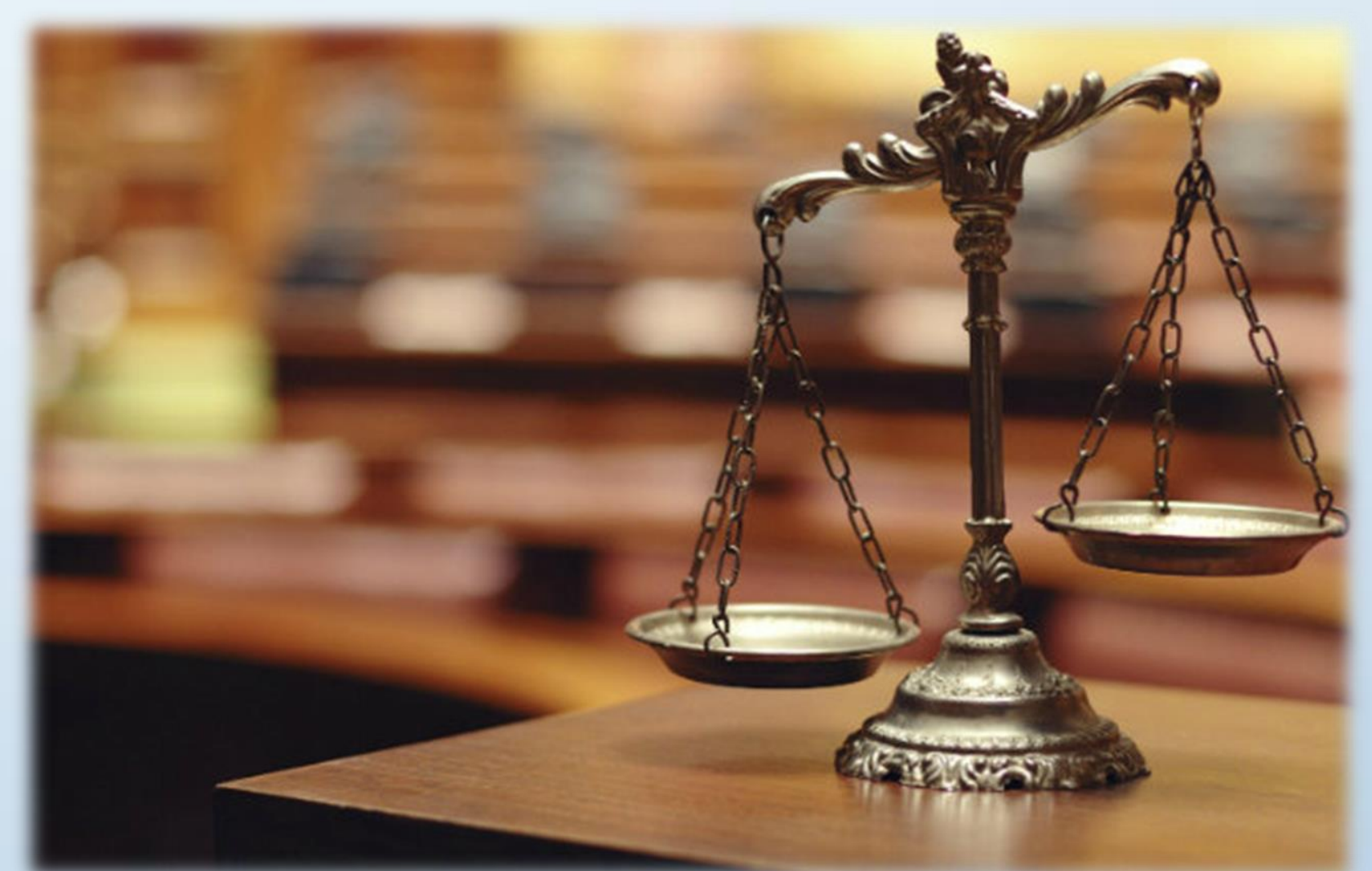


2xpse
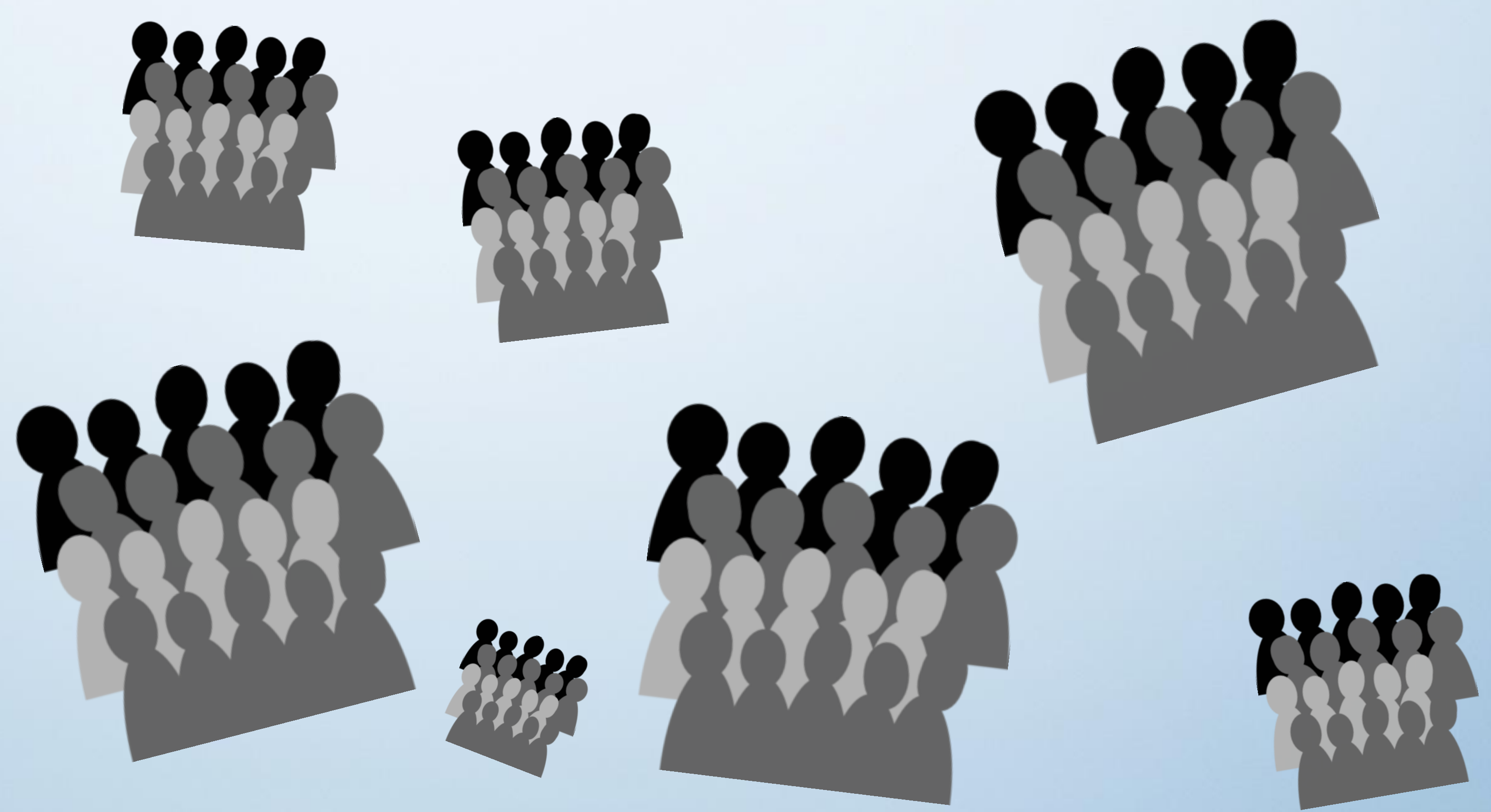
Characteristics of the SSRN audience

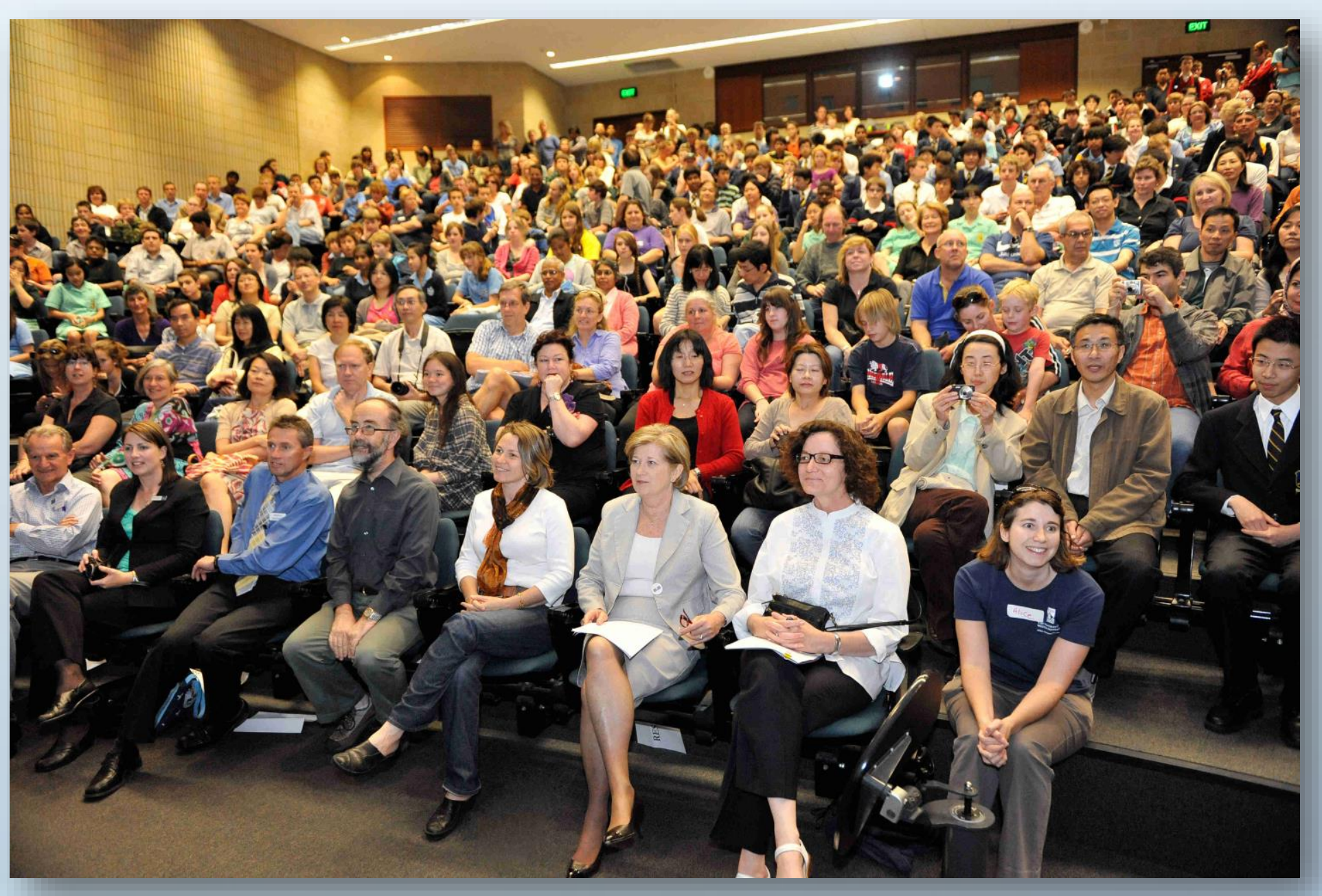




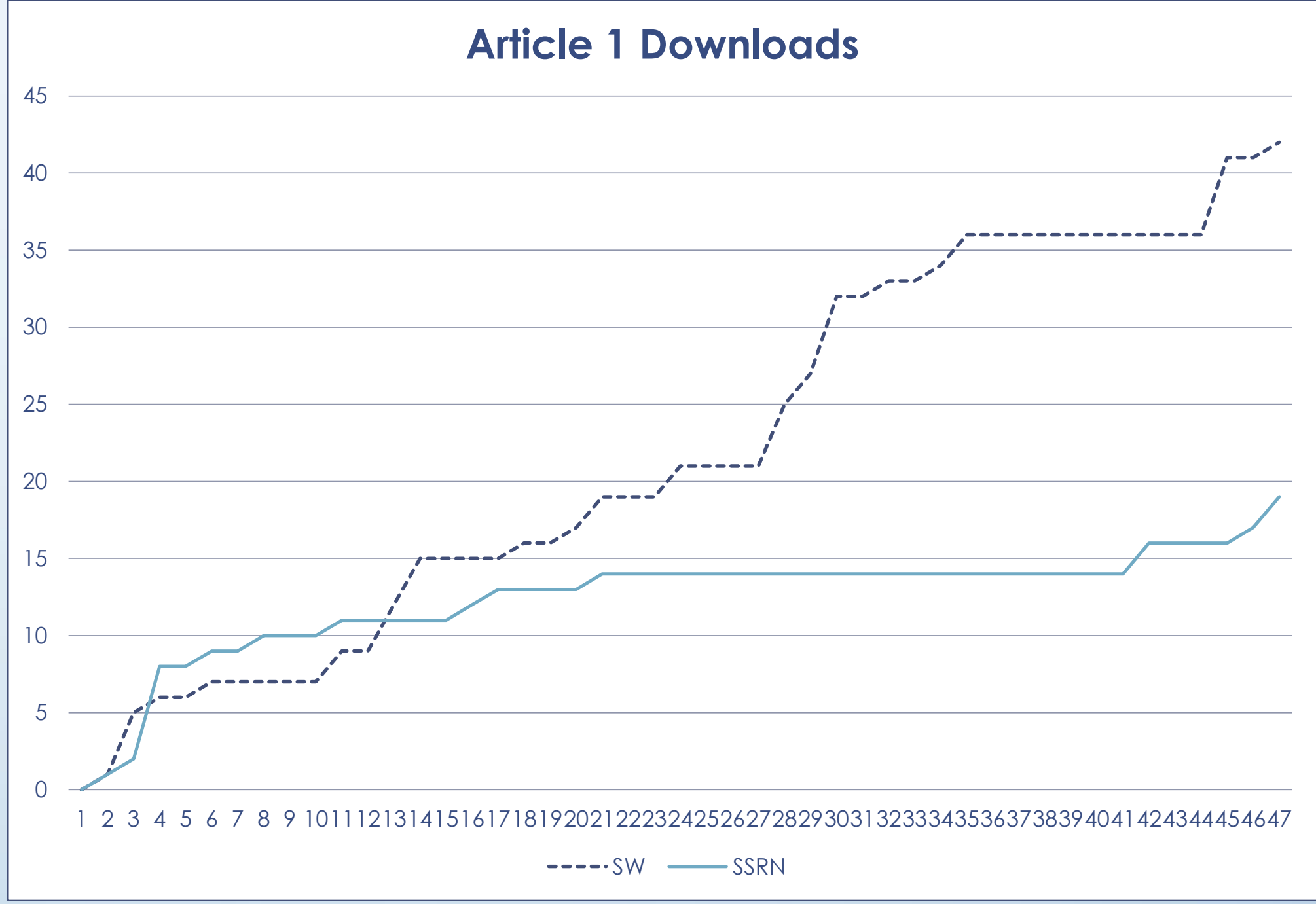

Selected Works versus SSRN Downloads (Weekly comparison from November 30, 2009 to October 18, 2010) 


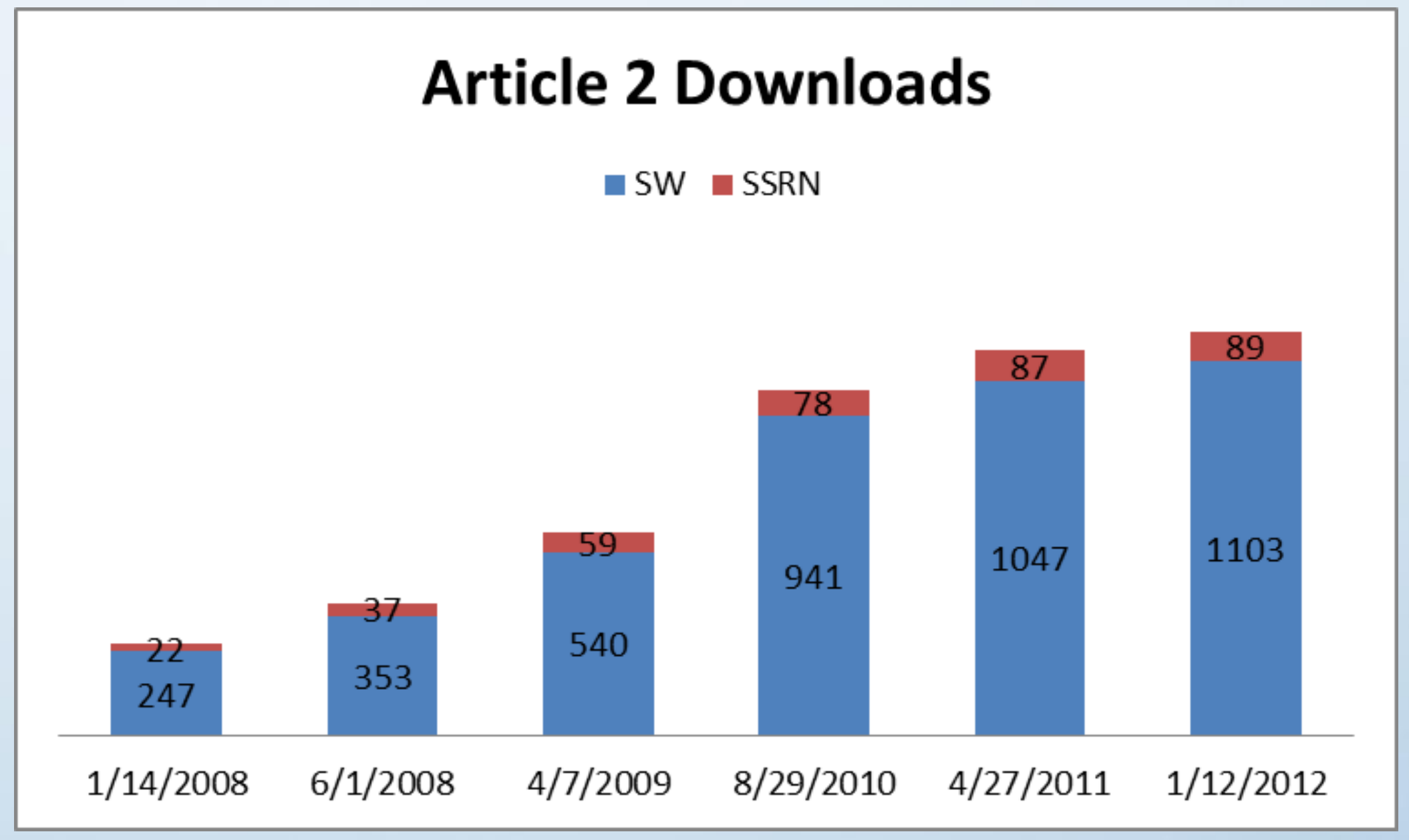




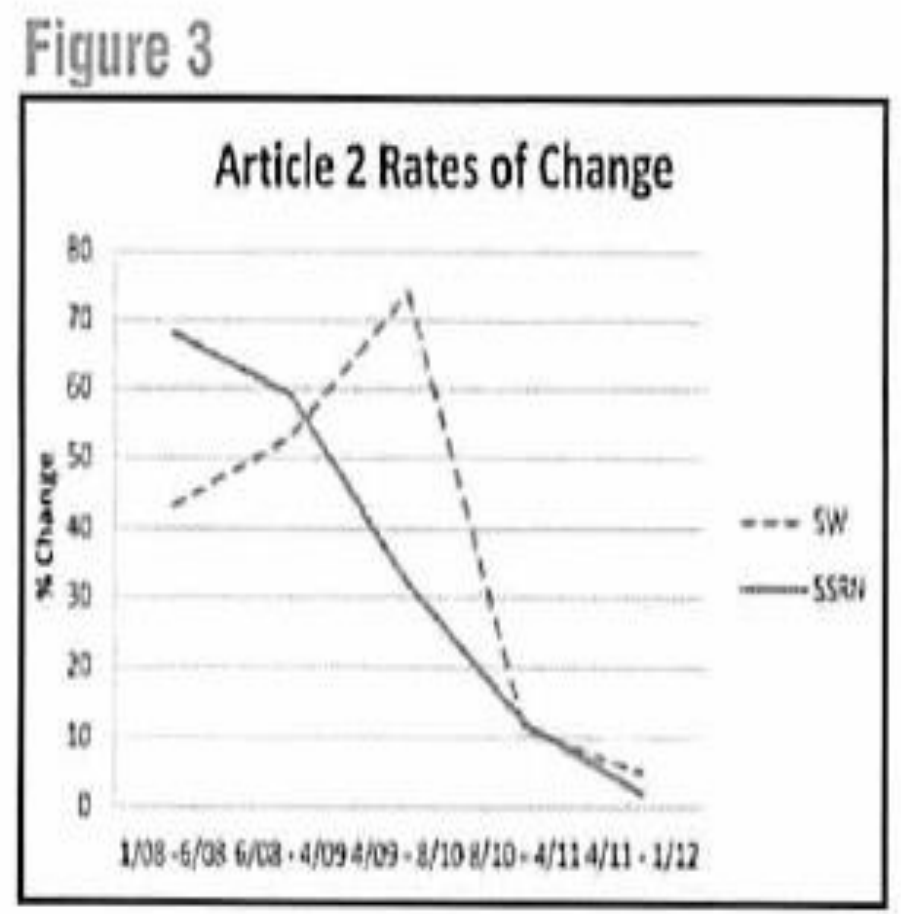

\section{SW versus SSRN Downloads}

(Percent change from 2008-2012) 


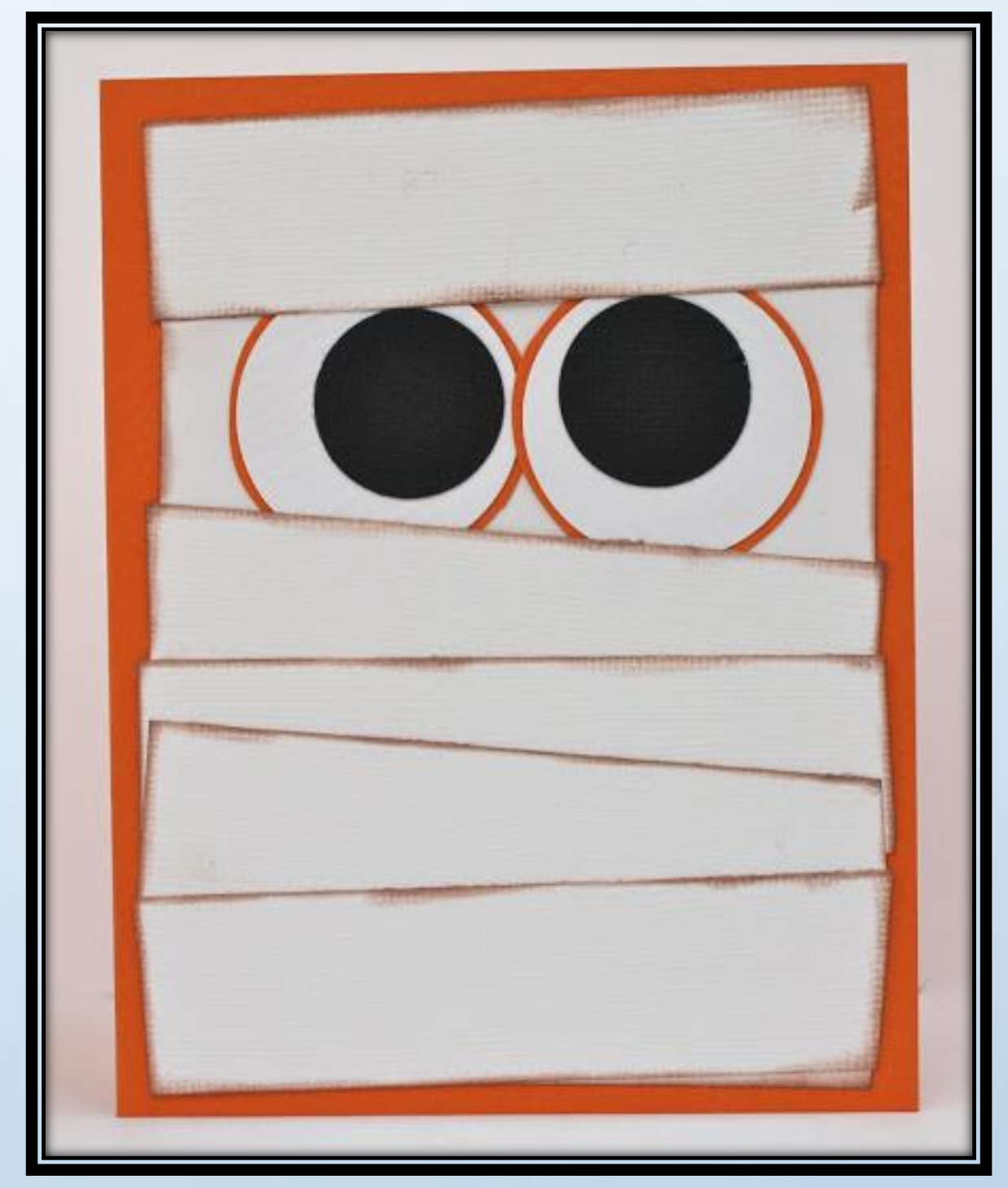




\section{The Open Access Advantage for American Law Reviews}

The Empirical Demonstration

James M. Donovan 
James M. Donovan and Carol A. Watson, Citation Advantage of Open Access Legal Scholarship, 103 Law Library Journal 553 (2011)

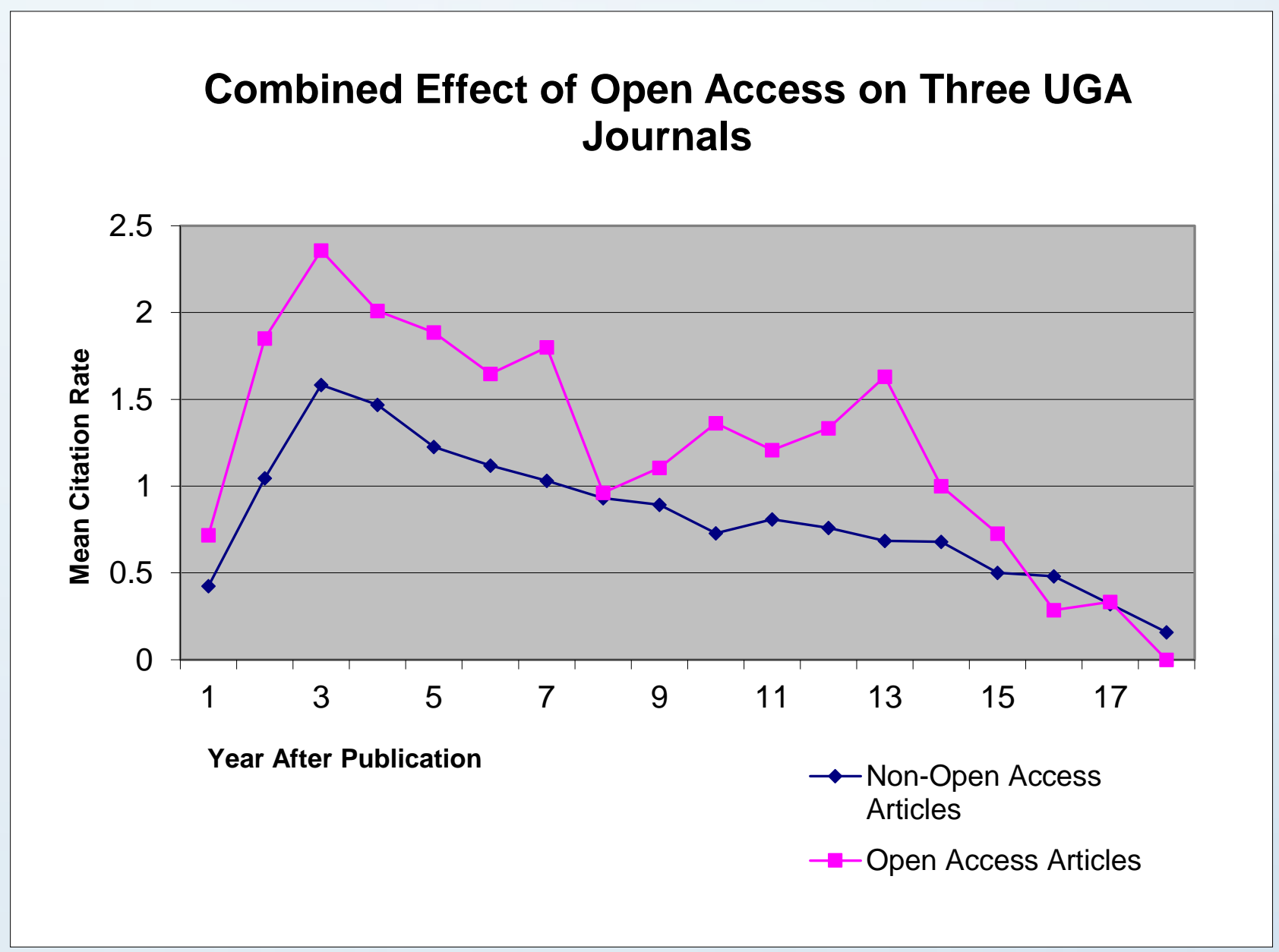

- 3 Journals

- 556 articles, 19902007

- Citations 19902009

- $58 \%$ averaged Open Access citation advantage for first 15 years after publication 
James M. Donovan, Carol A. Watson, Caroline Osborne, The Open Access Advantage for American Law Reviews, 97(1) Journal of the Patent and Trademark Office Society 1-25 (2015).

Originally released in the JPTOS online journal, EDISON (www.jptos.org/Edison) 


\section{Data Set}

- 30 flagship law reviews

- 10 U.S. News \& World Report "Tier 1" schools (Ranks 1-50)

- 9 schools from Tiers 2 and 3 (Ranks 51-147)

- 11 journals from Tier 4 (Ranks >147)

- Lead articles only from 1990-2010

- 6042 total

- 2553 Not available OA; 3489 OA

- Did not ascertain when OA access was provided relative to publication

- Citations from 1990-2012 


\section{Aggregated Citations by Law Review Literature (Years after Publication)}

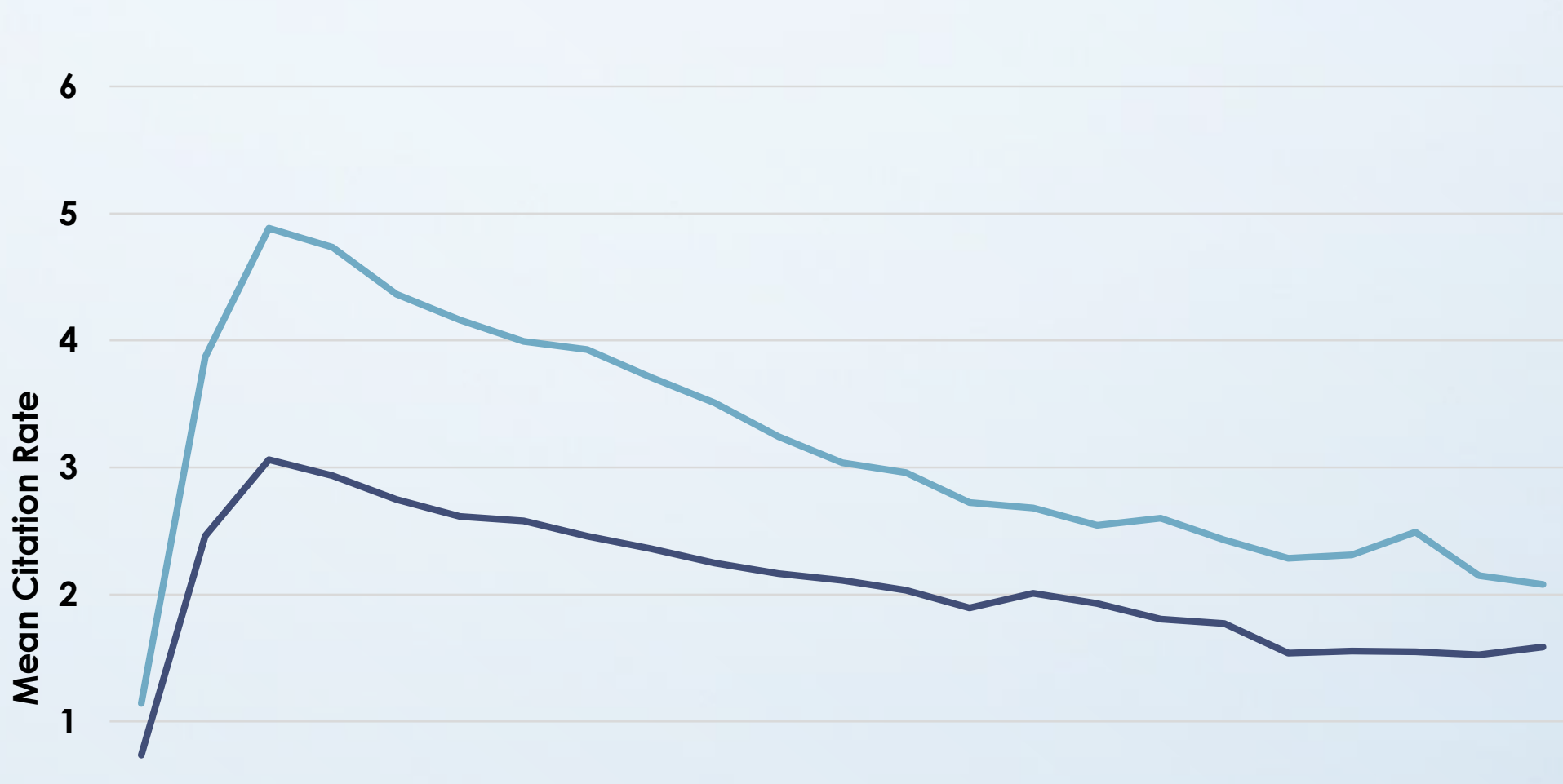

- $49 \%$ averaged Open Access citation advantage for first 23 years after publication 0 $\begin{array}{lllllllllllllllllllllll}1 & 2 & 3 & 4 & 5 & 6 & 7 & 8 & 9 & 10 & 11 & 12 & 13 & 14 & 15 & 16 & 17 & 18 & 19 & 20 & 21 & 22 & 23 \\ \text { Years after Publication } & & & & & & & & & \end{array}$

- 53\% for first 15 years (essentially replicating $58 \%$ 2011 result) 


\section{Law School Tiers}

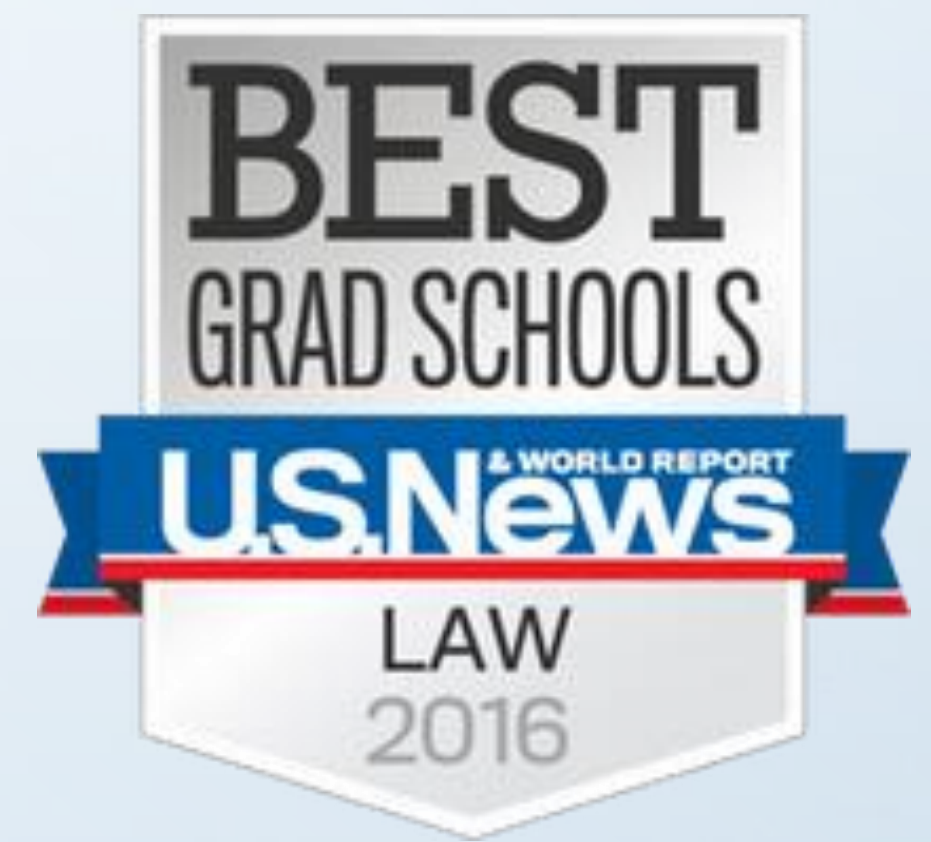




\section{Tier 1 Citations by Law Reviews (Years after Publication)}

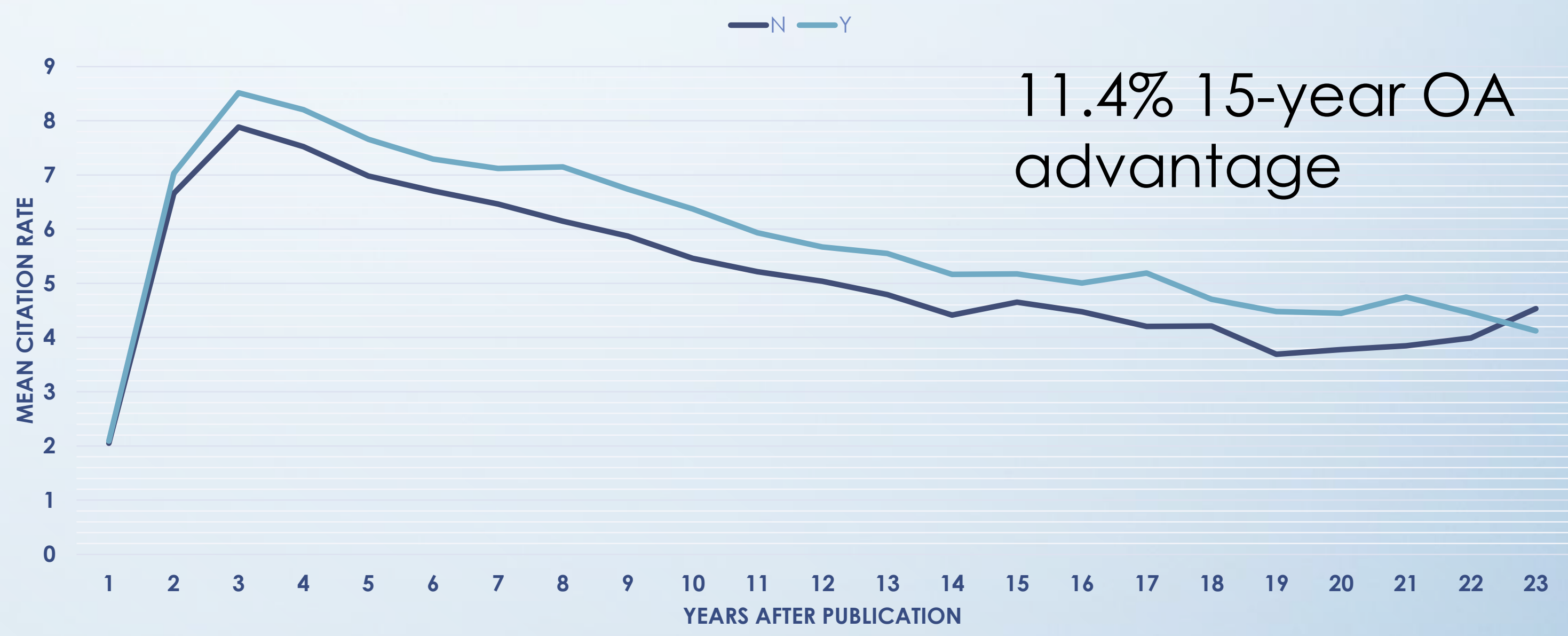




\section{Tiers 2-3 Citations by Law Reviews (Years after Publication)}

\section{2}

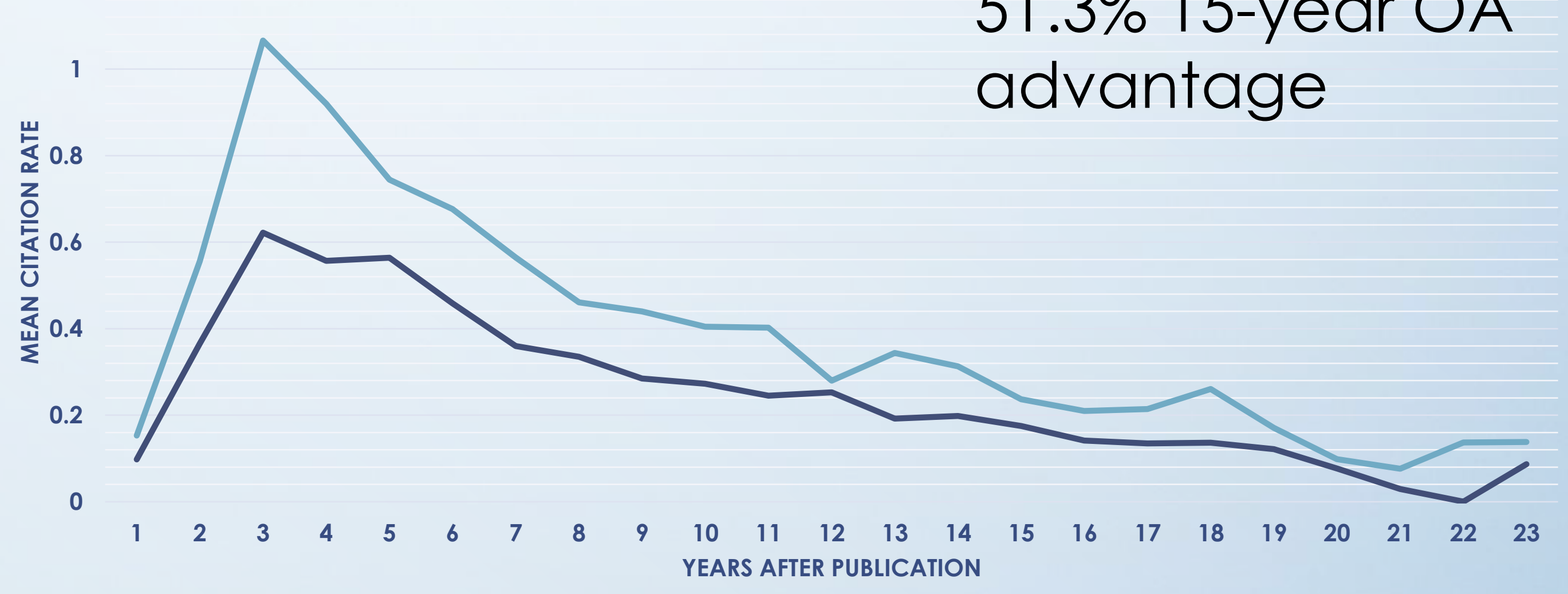




\section{Tier 4 Citations by Law Reviews (Years after Publication)}

1.2

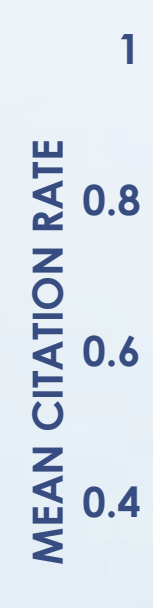

0.2

0

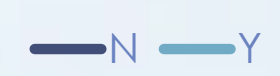

$$
\begin{aligned}
& 51.9 \% 15 \text {-year } \mathrm{OA} \\
& \text { advantage }
\end{aligned}
$$

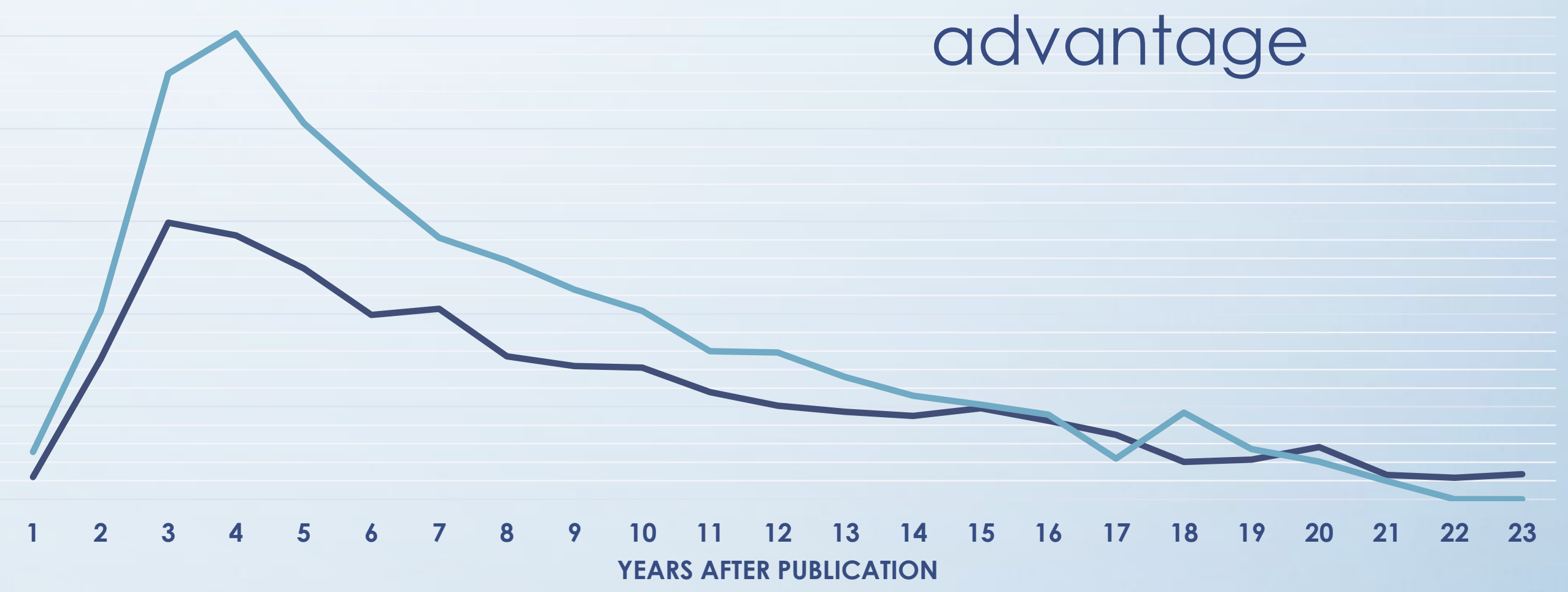




\section{LOW TOP TIER OA ADVANTAGE: 2 Interpretive Hypotheses}

1. Market Penetration Hypothesis: Contents of top journals always sought regardless of format

2. Topic Exhaustion Hypothesis: Narrow article focus combined with already wide citation of top journals leave little room for an advantage to appear

We favor the second explanation based upon data from the 2011 study comparing flagship and specialty journals revealed no halo effect of school reputation beyond the flagship title. 


\section{New Question}

What are the advantages of providing OA access to new work?

Instead of looking at citation rates relative to the dates of publication, let's look at them in the years they are actually received. A real-time analysis.

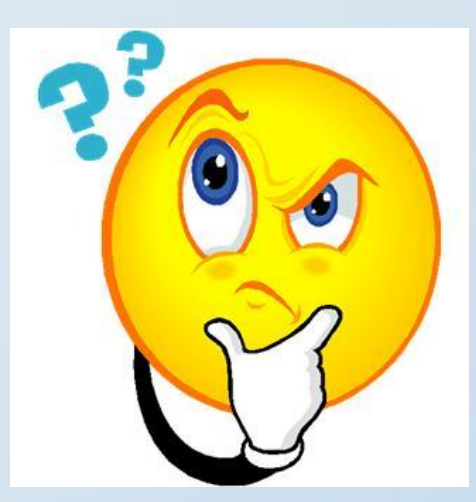




\section{Tipping Point}

Given the history of the development of the Internet (reviewed by Carol), we identified 2007 as the most defensible moment by which getting information from the web had become commonplace.

The "real-time" analysis therefore examines citations from 2007-2012. 


\section{Aggregated Citations by Law Reviews (Year of Citations)}

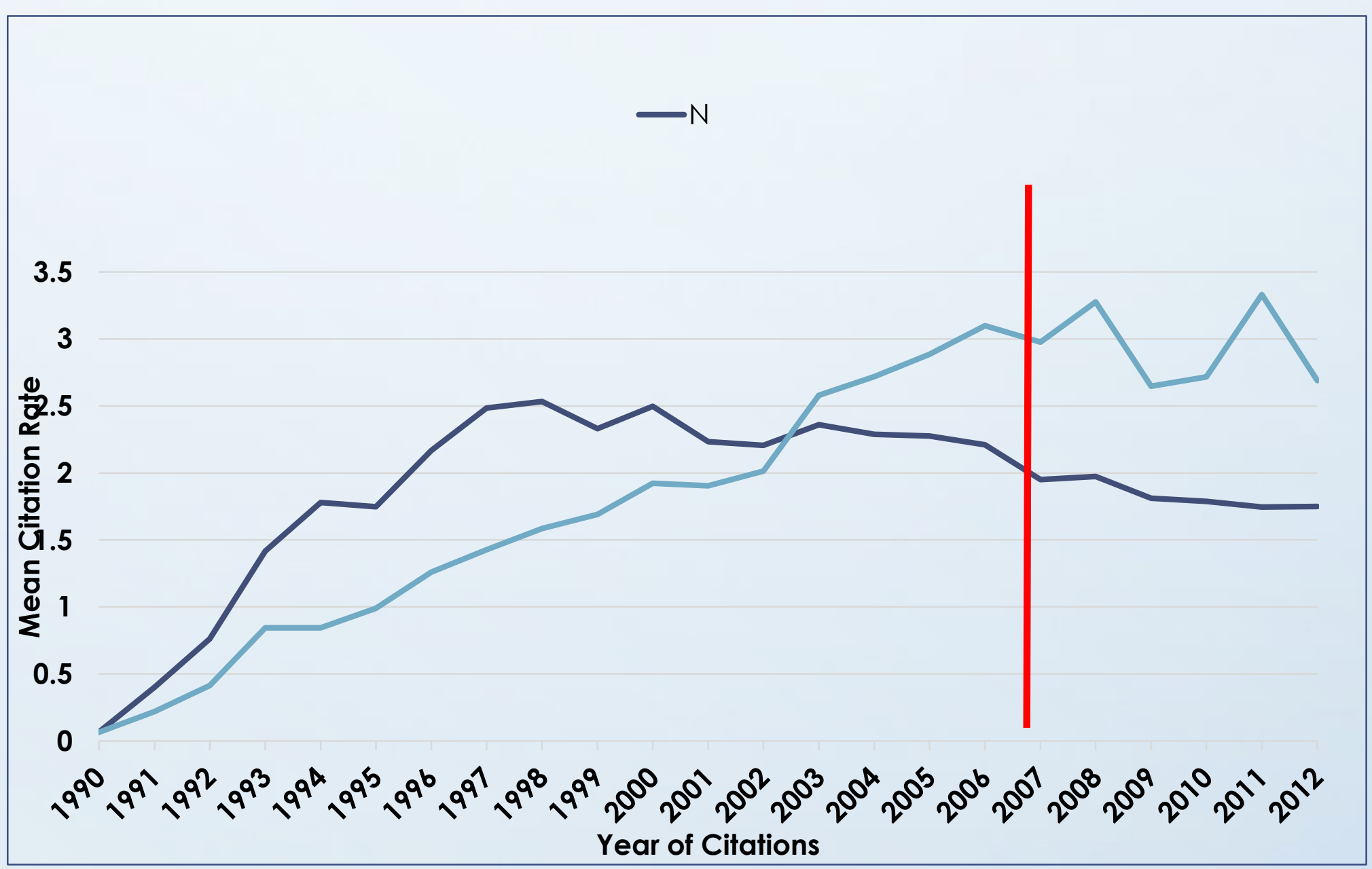

- $60.2 \%$ advantage over 2007-12

- Advantage of new works simultaneously released in print and $O A$, a figure undiluted by retroactive upload of older content. 


\section{Tier 1 Citations by Law Reviews (Year of Citations)}

Figure 6

Tier 1: Citations by Law Reviews

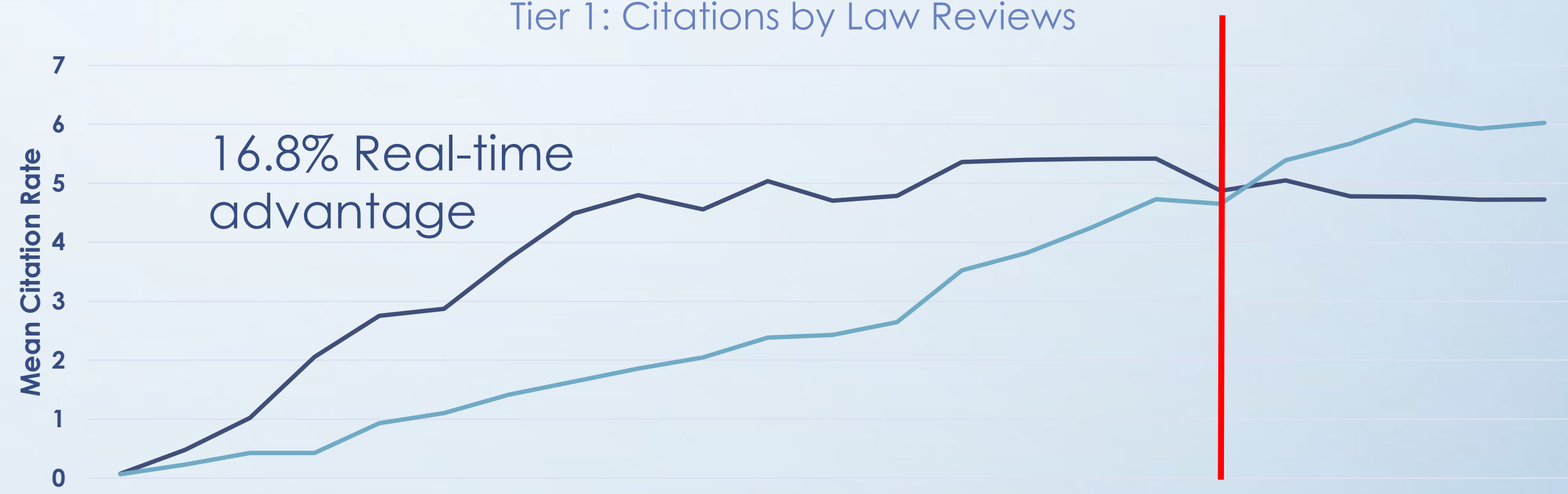

19901991199219931994199519961997199819992000200120022003200420052006200720082009201020112012 Year of Citations 


\section{Tiers 2-3 Citations by Law Reviews (Year of Citations)}

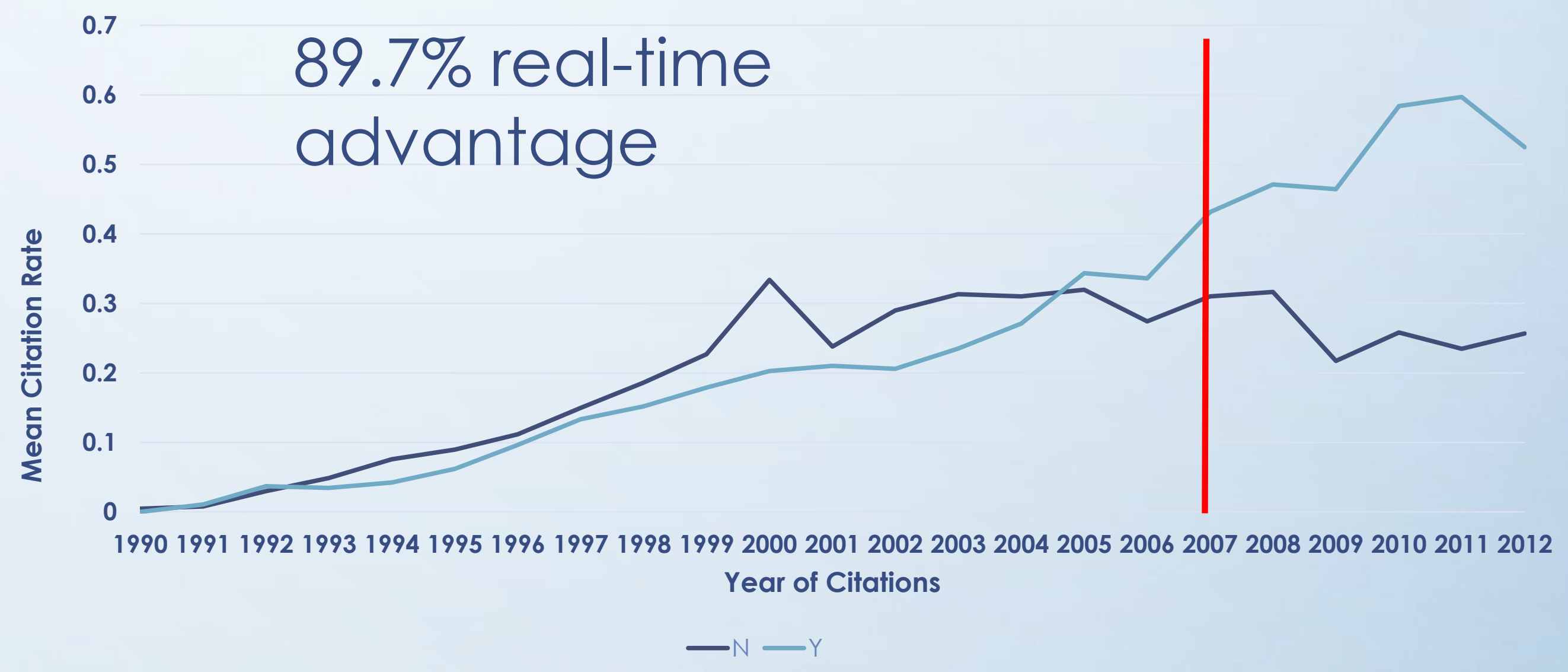




\section{Tier 4 Citations by Law Reviews (Year of Citations)}

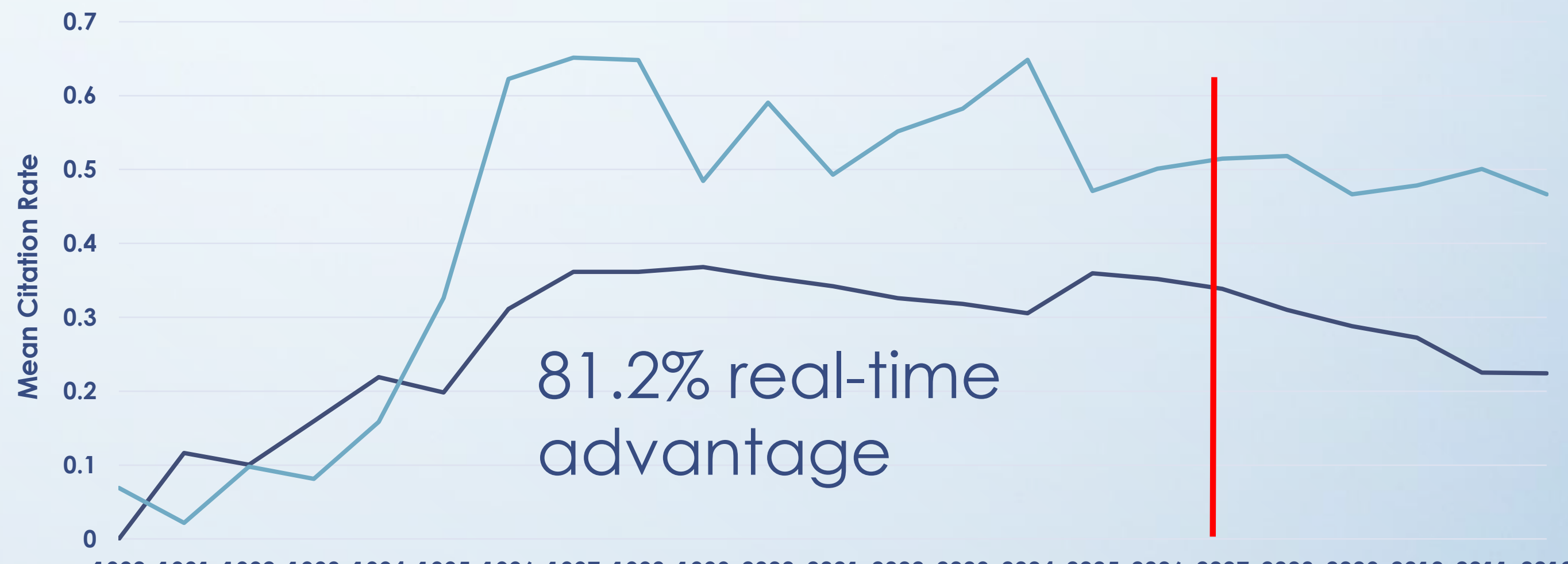

19901991199219931994199519961997199819992000200120022003200420052006200720082009201020112012 Year of Citations 


\section{General Conclusions}

- The OA advantage accrues disproportionately to flagship journals outside the top tier

- In general, for new works there is always a sizeable OA advantage

- For older works, the OA advantage increases the farther down the rankings because this may be the first time much of this work has been discovered 


\section{CITATIONS IN COURT DECISIONS}

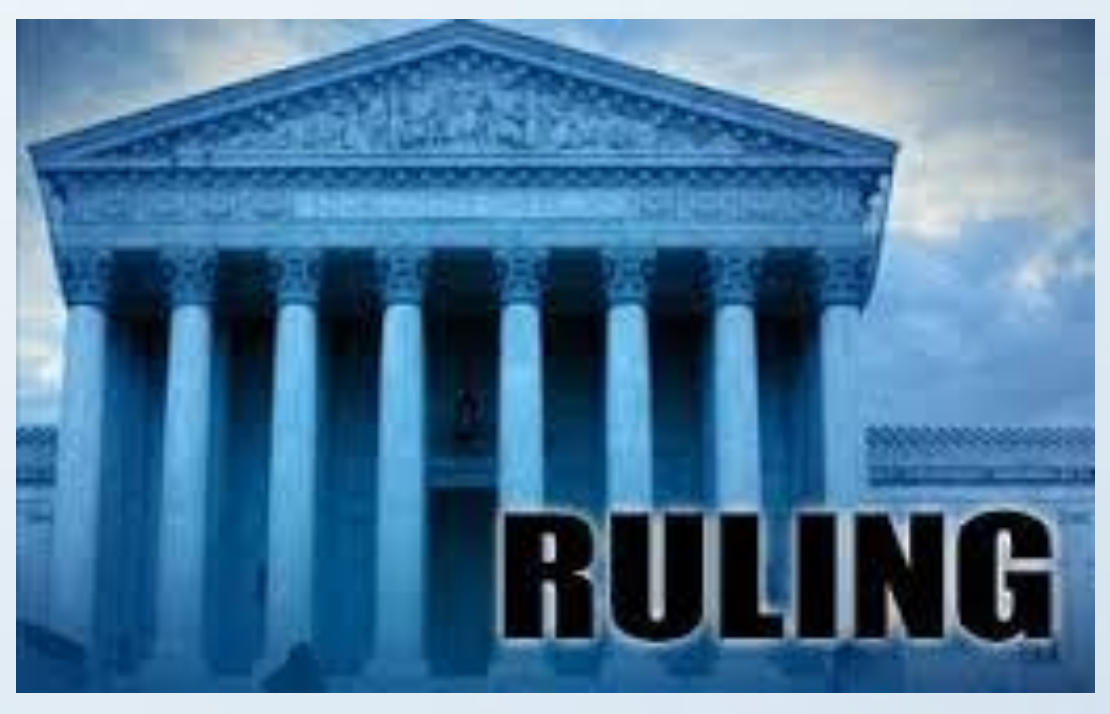




\section{Aggregated Journal Citations by Case Law (Years after Publication)}

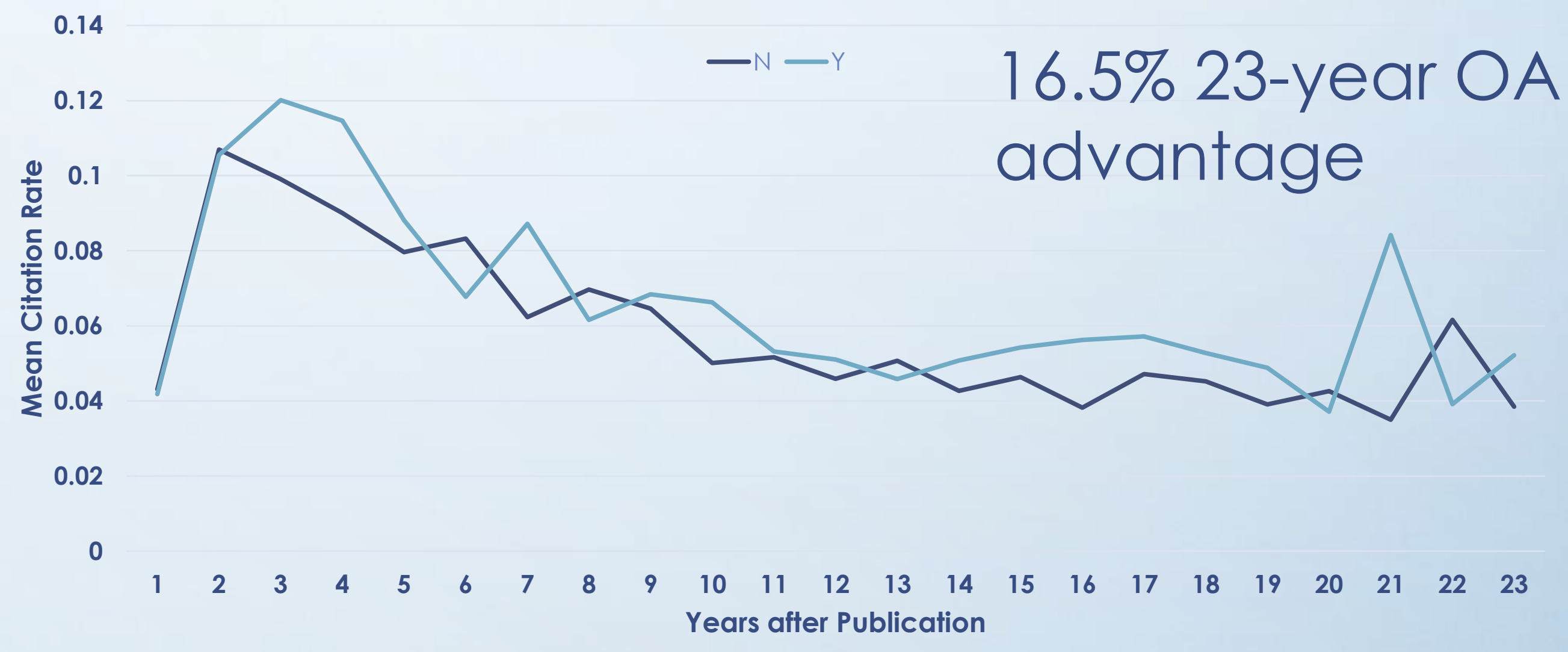




\section{Aggregated Journal Citations by Case Law (Year of Citations)}

$0.12 \quad 41.4 \%$ Re Olime

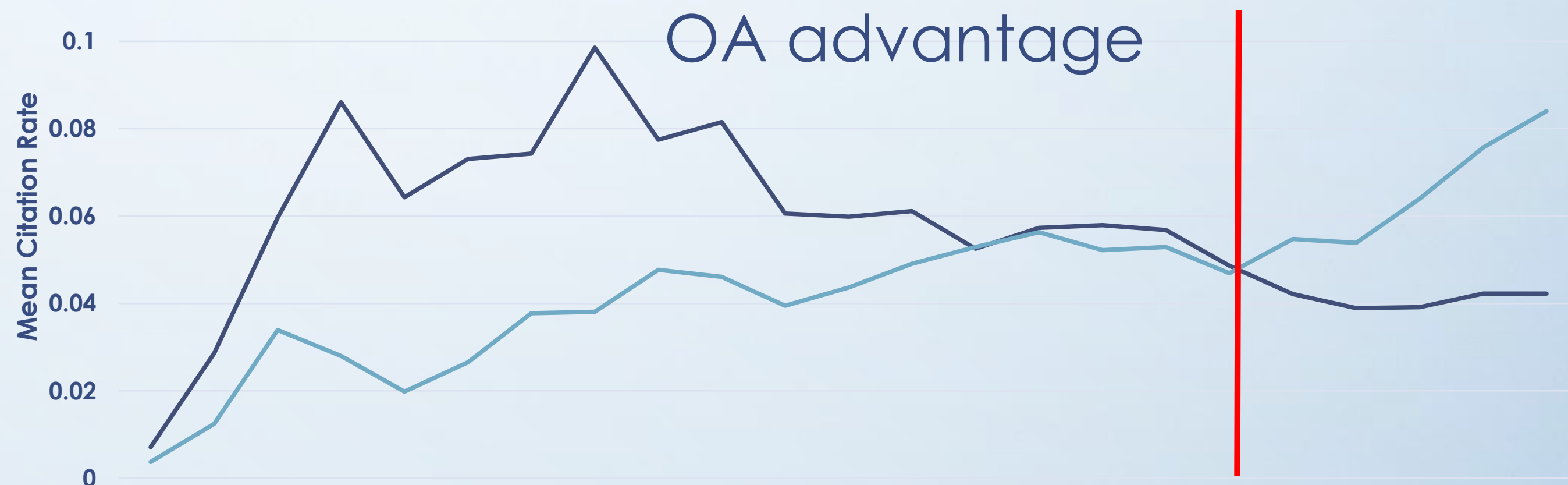

19901991199219931994199519961997199819992000200120022003200420052006200720082009201020112012 Year of Citations 


\section{Tier 1 Citations by Court Decisions (Year of Citations)}

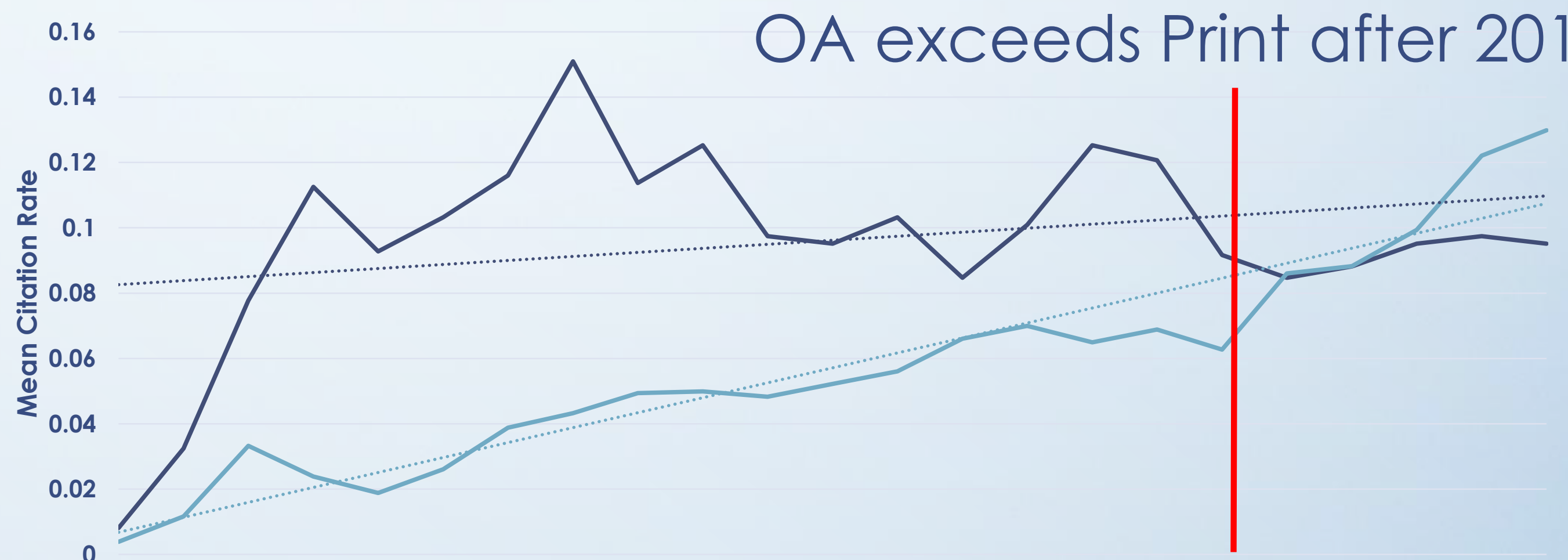

19901991199219931994199519961997199819992000200120022003200420052006200720082009201020112012 Year of Citations 


\section{Tiers 2-3 Citations by Court Decisions (Year of Citations)}

0.12

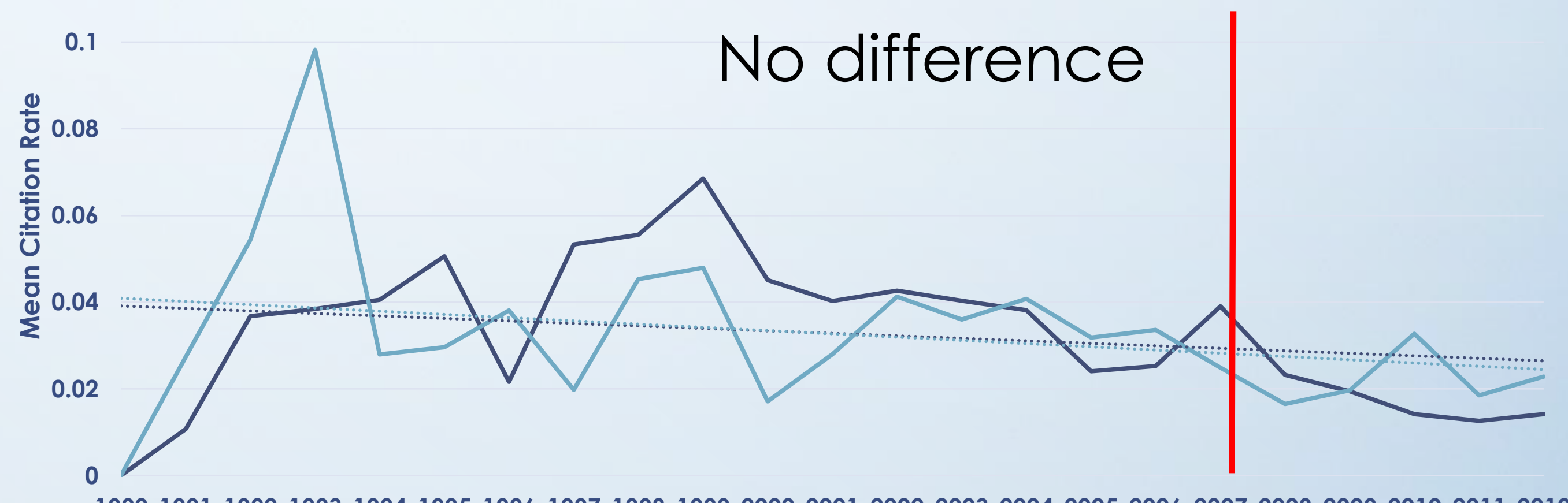

19901991199219931994199519961997199819992000200120022003200420052006200720082009201020112012 Year of Citations 


\section{Tier 4 Citations by Court Decisions (Year of Citations)}

OA advantage small but consistent

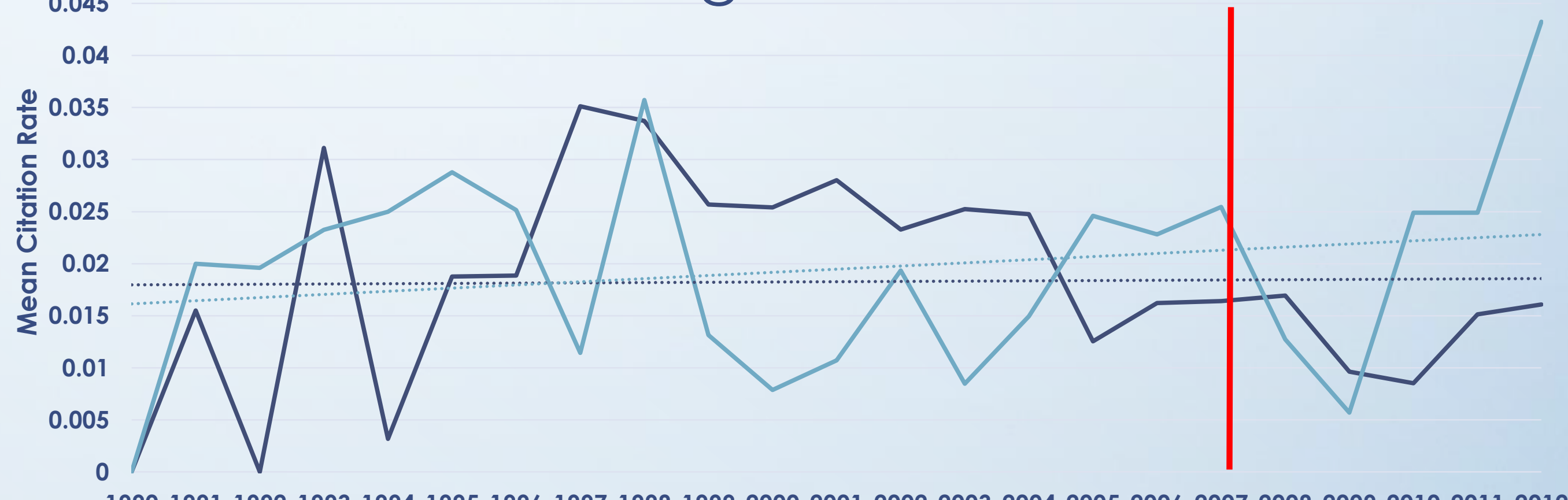

19901991199219931994199519961997199819992000200120022003200420052006200720082009201020112012 Year of Citations 


\section{Summary}

- General OA advantage over 15 years in flagship law reviews of $53 \%$

- Half of these citations will be given in first six years after publication

- OA advantage is less for top tier journals because their contents routinely saturate fheir topical areas regardless of format

- Correlatively, the general OA advantage is magnified for lower tier titles due to heightened discoverability 


\section{Summary cont'd}

- Looking only at citation to new content (2007-2012), the total OA advantage rises to $60.2 \%$.

- Tiered results are even more dramatic: Tier $1=$ $16.8 \%$, Tiers $2-389.7 \%$, and Tier 4 articles see an $81.2 \%$ advantage.

- Lower tier journals see the most citation benefit from retrospective upload of older publications

- This pattern applies to a lesser extent to citations by court decisions. 


\section{Conclusions}

- For authors: OA advantage is real, sizeable, and consistent. Participate in OA projects!

- For journals: It should go without saying: Put your new content available in OA platforms. For all but the most elite, retrospective projects will increase audience for published works and find hidden readers. 


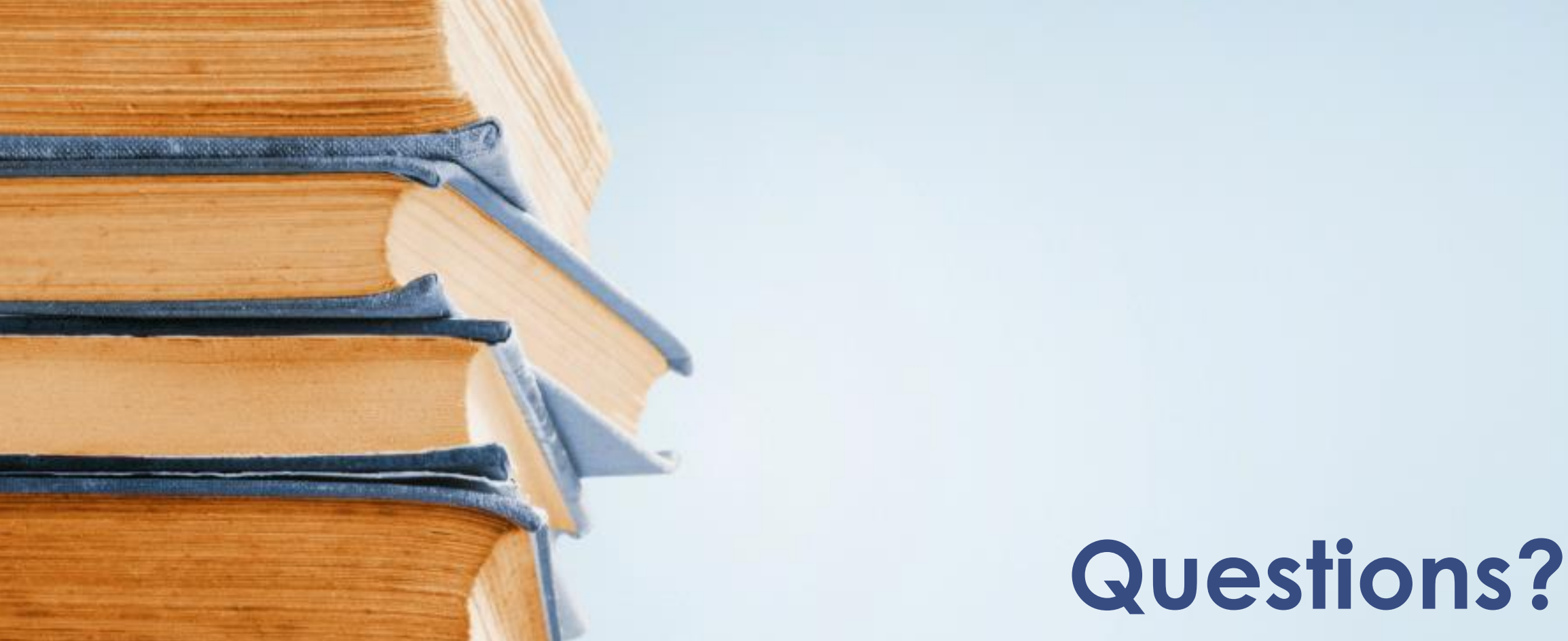

Questions? 